Journal of Engineering and Applied Sciences 7 (4): 306-325, 2012

ISSN: $1816-949 \mathrm{X}$

(C) Medwell Journals, 2012

\title{
On the Coexistence of Ionospheric Positive and Negative Storm Phases During January to December, 2000 Geomagnetic Activities at East Asian Sector
}

\author{
Adebesin B. Olufemi \\ Space Weather Research Group, Department of Industrial Physics, \\ College of Science and Engineering, Landmark University, \\ P.M.B. 1001, Omu Aran, Kwara State, Nigeria
}

\begin{abstract}
In this study, the analyses of the peak monthly geomagnetic storms observed between January to December, 2000 had been presented. This study is based on data from a network of ionosondes stations located within the East Asian latitudinal sector of $40-65^{\circ} \mathrm{N}$. It was found that the effects of ionization depletion at an F2 layer maximum observed at all stations during some of the events are as a result of rapid heating of the polar atmosphere during energy income from the magnetosphere. On the contrary, the positive storm phases observed can be attributed partly to an Eastward electric field which will move the mid-latitude ionospheric F region plasma to higher altitudes with lower recombination, resulting in increases of the electron density. It is therefore, suggested that this action may be responsible for the observed long-duration positive storm for the 12 th February and 5th October, 2000 geomagnetic activities. On the geoeffectiveness of the F2 ionosphere with interplanetary and solar wind parameters, the correlation percentage between the $\mathrm{F} 2$ critical frequency deviation $\mathrm{D}(\mathrm{foF} 2)$ and IMF $\mathrm{Bz}$ are higher at most ionosonde stations than between $\mathrm{D}(\mathrm{foF} 2)$ and $\mathrm{Dst}$. In relation to the flow speed V, all the stations had a good correlation ( $>58 \%)$ except at Petropavlovsk. The average correlation percentage for the $\mathrm{F} 2$ ionosphere against the Dst, flow speed $\mathrm{V}$ and $\mathrm{Bz}$ are 40.5, 60.3 and 46.4 , respectively. This suggests that the plasma flow speed is the most geoeffective parameter with the $\mathrm{F} 2$ ionosphere; irrespective of the latitudinal position (low latitude is not considered here). For $\mathrm{D}(\mathrm{foF} 2)$ versus $(\mathrm{V} \times \mathrm{Bz})=\mathrm{E}$, the high latitude station of Salekhard had the highest correlation percentage (71.4\%), followed by Magadan $(60.4 \%)$, Tashkent $(42.3 \%)$, Novosibirk (10\%) and Petropavlovsk (negligible). From these, the following were deduced: the increase in percentage correlation of $(\mathrm{Vx} \mathrm{Bz})=\mathrm{E}$ against $\mathrm{D}(\mathrm{foF} 2)$ is directly proportional to the increase in the latitudinal position of each station; the stations with more occurrences of electron density enhancement are those whose altitudes are $>100 \mathrm{~m}$; an average value of $37.5 \%$ correlation for $(\mathrm{V} \mathrm{x} \mathrm{Bz})=\mathrm{E}$, versus $\mathrm{D}(\mathrm{foF} 2)$ showed that $\mathrm{V}$ is more geoeffective if it were to be $\mathrm{Bz}$, the percentage of value would have been $\geq 50 \%$.
\end{abstract}

$\underline{\text { Key words: } \text { Magnetosphere, electric field, critical frequency deviation, ionization, ionosphere, mid-latitude }}$

\section{INTRODUCTION}

Some excellent researches on ionospheric storms has been published during the past four decades. It has been difficult or impossible to develop any unique theory that can explain the ionospheric responses at all latitudes for storms in general. Electrodynamic drifts, meridional winds, rapid changes in atmospheric heating and thermal expansion etc., have been invoked and suggested by many researchers. However, ionospheric storms represent large global disturbances in the $\mathrm{F}$ region electron density in response to geomagnetic storms. Positive and negative storm phases are used to describe increases and decreases in the ionospheric electron density during storms. Positive storm phases occur more frequently in
Winter and negative storm phases often occur in Summer (Rodger et al., 1989). So far mid- and low-latitude F2 layer storm effects have been studied more extensively than high-latitude ones. This is partly due to the difficulties with ground-based ionosonde observations during geomagnetically disturbed periods. In addition, the highlatitude $\mathrm{F} 2$ region is very variable, being strongly influenced by magnetospheric processes; in particular, substantial electric fields are usually present during geomagnetic storms. These electric fields and the corresponding horizontal plasma drifts can strongly perturb the electron density distribution at F2 layer heights. Neutral composition and temperature changes are the other source of negative F2 layer storm effects. Hence, the aim of the present research is to study the physical

Corresponding Author: Adebesin B. Olufemi, P.O. Box 1330, Ijebu-Ode, Ogun State, Nigeria 
mechanism and to estimate the contribution of various processes that affects the ionospheric F2 layer (using the critical frequency foF 2 ) during the peak storm activities (inh each month of the year 2000) at 5 general ionospheric stations in the East Asian geomagnetic zone.

\section{MATERIALS AND METHODS}

The OMNI data base is a convenient and widely used source for studying intense magnetic storms (http://nssdc.gsfc.nasa.gov/omniweb/ow/html). For the purpose of this study, 12 storm events occurring in the year 2000 are being understudied. The 12 storms are the peak geomagnetic activity occurring in each month of the year 2000 (Table 1). All are intense, except for the one of January, 23 (for the month of Jan.), June, 26 (for Jun.) and December, 23 (for Dec.). According to Gonzalez et al. (1994), intense storms are those with peak of Dst of $-100 \mathrm{nT}$ or less moderate storms fall between -50 and $-100 \mathrm{nT}$ and weak storms are those between -30 and $-50 \mathrm{nT}$. However, the interplanetary, geomagnetic and solar wind parameters data used are the plasma proton density, the solar wind flow speed $V\left(\mathrm{~km} \mathrm{sec}^{-1}\right)$, the average magnetic field $\mathrm{B}(\mathrm{nT})$, the IMF Bz (nT), the plasma temperature $\mathrm{T}(\mathrm{K})$, the low latitude magnetic index Dst (nT), plasma beta and the electric field $\left(\mathrm{mV} \mathrm{m}^{-1}\right)$. All are from the OMNI database and mostly from the IMP 8 Spacecraft. Table 1 shows the peak storm events and days for each month with corresponding values of flow speed, IMF Bz (in GSM) and occurrence time at minimum peak Dst value. Total 5 out of this 12 geomagnetic activities are discussed in this study. This are February 11-14 (Fig. 1), August 11-14 (Fig. 2), September

Table 1: Maximum geomagnetic activity days for each of the months in the year, 2000 with corresponding peak Dst and time, flow speed and IMF Bz (GSM)

\begin{tabular}{llccrc}
\hline Storm date & Months & Peak Dst & $\mathrm{V}\left(\mathrm{km} \mathrm{sec}^{-1}\right)$ & \multicolumn{1}{c}{$\mathrm{Bz}$} & Peak Dst time \\
\hline Jan. 23, 2000 & Jan & -97 & 360 & -14.1 & 00.00 \\
Feb. 12, 2000 & Feb & -133 & 568 & -1.4 & 11.00 \\
Mar. 31, 2000 & Mar & -60 & 396 & -4.9 & 11.00 \\
Apr. 7, 2000 & Apr & -288 & 571 & -4.7 & 00.00 \\
May 24, 2000 & May & -147 & 642 & -7.1 & 08.00 \\
Jun. 26, 2000 & Jun & -76 & 540 & -7.8 & 17.00 \\
Jul. 15, 2000 & Jul & -301 & 1030 & -3.7 & 00.00 \\
Aug. 12, 2000 & Aug & -235 & 613 & -13.9 & 09.00 \\
Sep. 17, 2000 & Sep & -201 & 794 & -5.8 & 23.00 \\
Oct. 5, 2000 & Oct & -182 & 523 & -10.4 & 13.00 \\
Nov. 6, 2000 & Nov & -159 & 570 & 5.3 & 21.00 \\
Dec. 23, 2000 & Dec & -62 & 323 & -12.7 & 04.00 \\
\hline
\end{tabular}

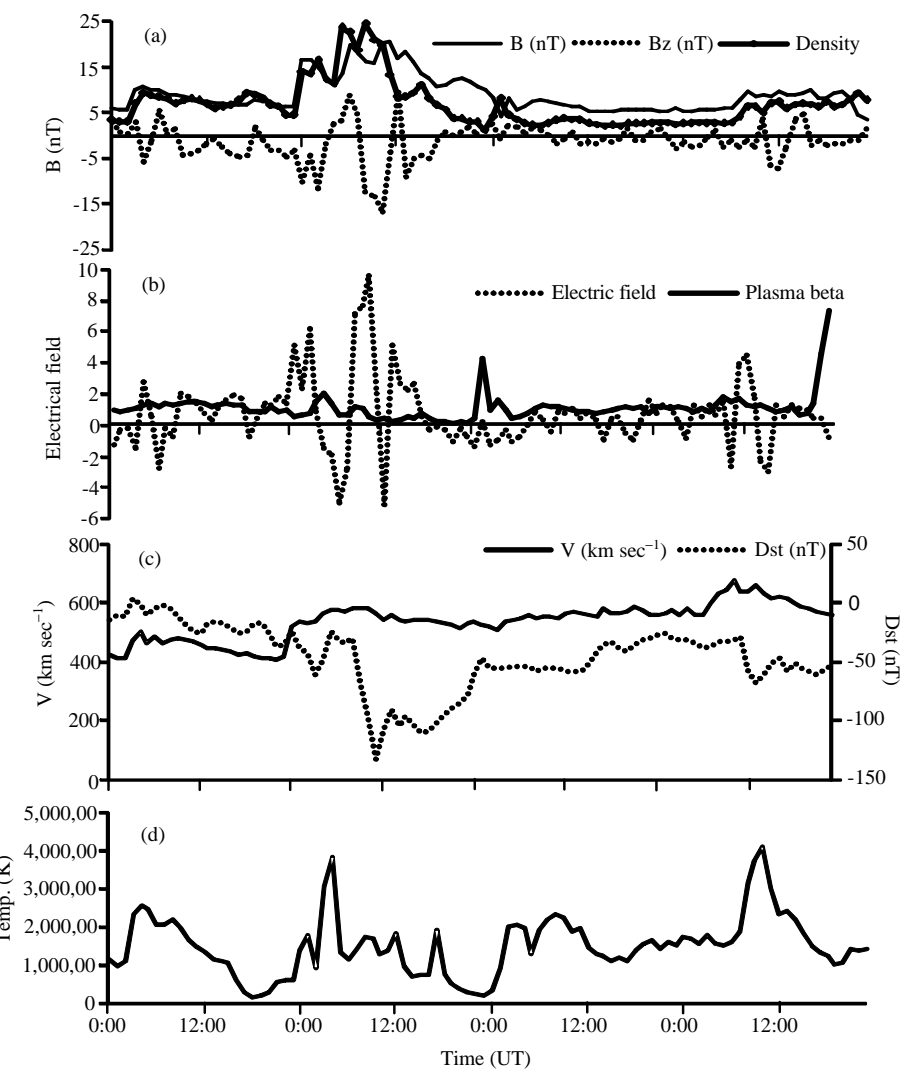

Fig. 1: a-d) Response plots of the geomagnetic, interplanetary and solar wind parameters for the storm of February 12 , 2000 and spanning February 11-14, 2000 

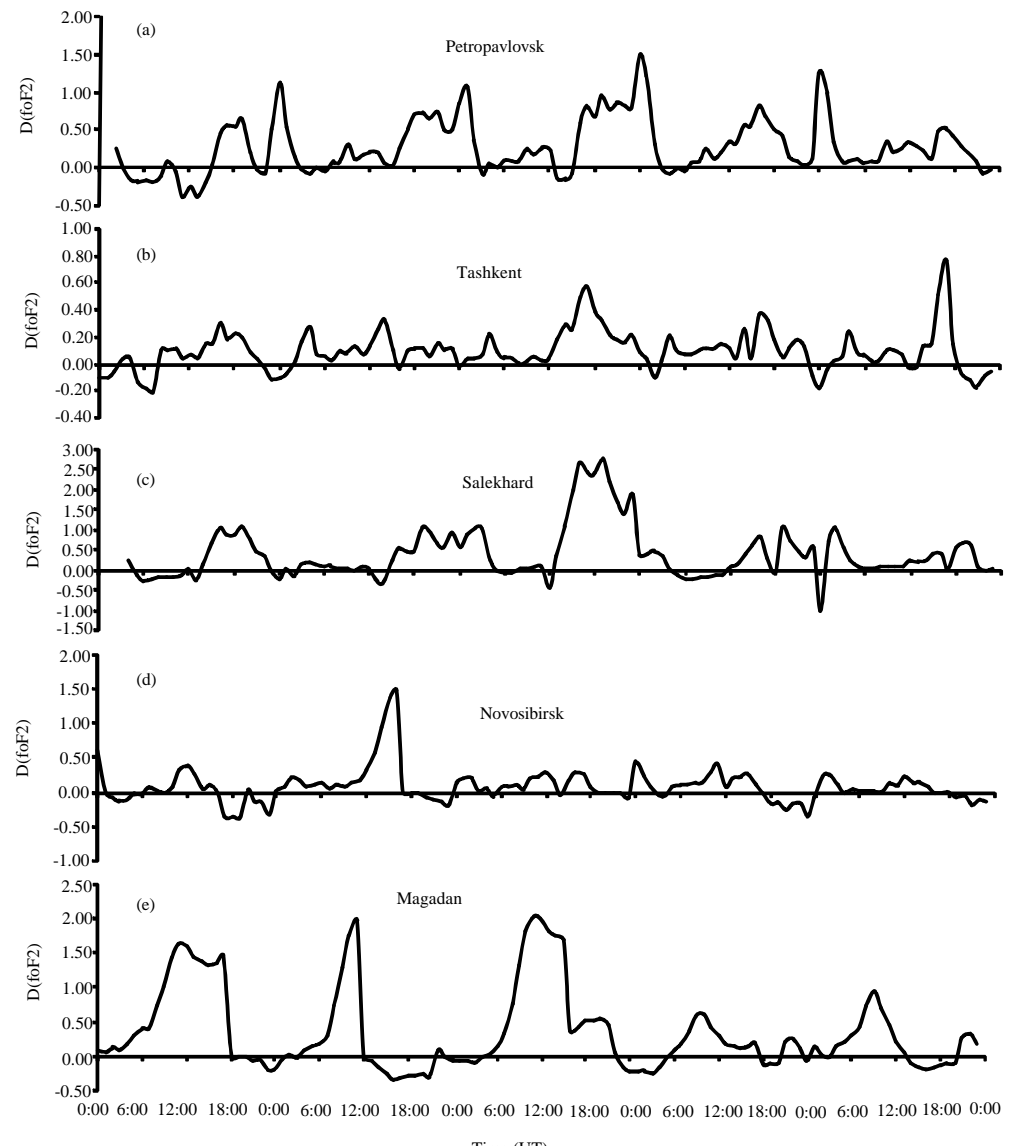

Time (UT)

Fig. 2: a-e) The ionospheric observations of the storm of February 12, 2000

16-19 (Fig. 3), October 4-7 (Fig. 4) and July 14-17 (Fig. 5), all in the year 2000. The 3 of these are part of the 9 great geomagnetic storms that occurred during the Solar cycle 23 (i.e., between 1996 and 2006). Year 2000 also falls between the period of rise and maximum of Solar cycle 23 (Dal Lago et al., 2004).

On the other hand, the ionospheric data used consists of hourly values of the $\mathrm{F}$ layer critical frequency foF2 obtained from some of the National Geophysical Data Center's in Space Physics Interactive Data Research (SPIDR) network of ionosonde stations located in the East Asian sector (predominantly Russia region) (Table 2).

The $\mathrm{F}$ layer critical frequency foF 2 is used because of its direct relationship with the $F$ layer peak electron density $\mathrm{NmF} 2$ (which is a measure of positive or negative storm effects through its significant increases or decreases about the mean position, respectively) i.e.:

$$
\text { fo } F 2(\mathrm{~Hz})=9.0 \mathrm{x} \sqrt{\mathrm{NmF} 2\left(\mathrm{~m}^{-3}\right)}
$$

\begin{tabular}{llrlrr} 
Table 2: List of ionosonde stations in the East Asian sector \\
\hline \multicolumn{7}{c}{$\begin{array}{c}\text { Geographical cord. } \\
\text { Station }\end{array}$} & Code & Altitude (m) & Lat. $\left({ }^{\circ} \mathrm{N}\right)$ & Long. $\left({ }^{\circ} \mathrm{E}\right)$ & berence \\
betweenLST & and (h) \\
\hline Petropavlovsk & PK553 & 50 & 52.97 & 158.45 & +12 \\
Tashken & TQ241 & 480 & 41.16 & 69.13 & +5 \\
Salekhard & SD266 & 66 & 66.59 & 66.61 & +5 \\
Novosibirsk & NS355 & 111 & 55.04 & 82.55 & +7 \\
Magadan & MG560 & 610 & 60.21 & 151.03 & +11 \\
\hline
\end{tabular}

For the purpose of this research, researchers concentrate only on the high and mid-latitude stations. The high latitude ones are Salekhard $\left(66.59^{\circ} \mathrm{N}\right)$ and Magadan $\left(60.20^{\circ} \mathrm{N}\right)$ while the mid-latitude stations are Petropavlovsk $\left(52.97^{\circ} \mathrm{N}\right)$, Tashkent $\left(41.16^{\circ} \mathrm{N}\right)$ and Novosibirsk $\left(55.04^{\circ} \mathrm{N}\right)$. It is important to note that paucity of data at most stations during the days under investigation restricted the choice of ionosonde stations.

Moreover, the criterion used in selecting the stations is such that storm variations represented real changes in electron density and not simply redistribution of the existing plasma. However, the F2 region response to a 


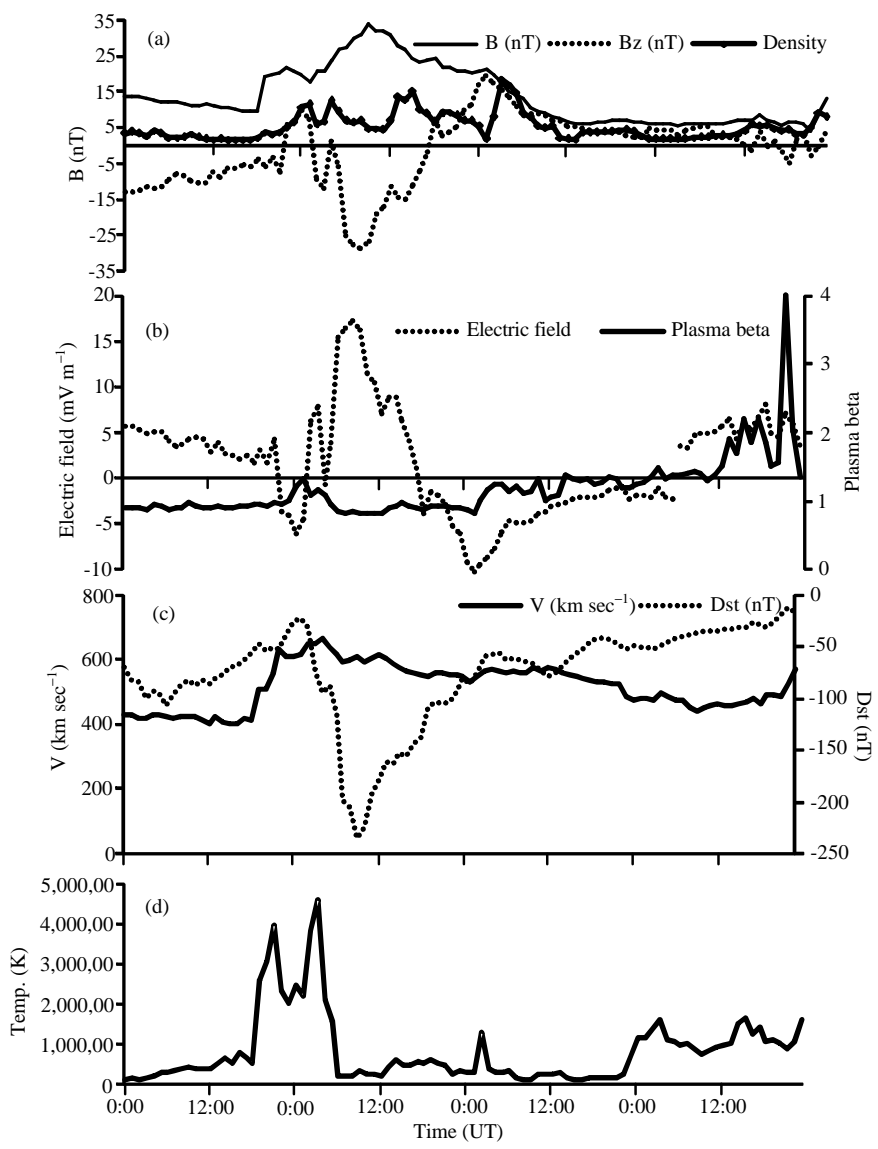

Fig. 3: a-d) Response plots of geomagnetic, interplanetary and solar wind parameters for the storm of August 11-14, 2000

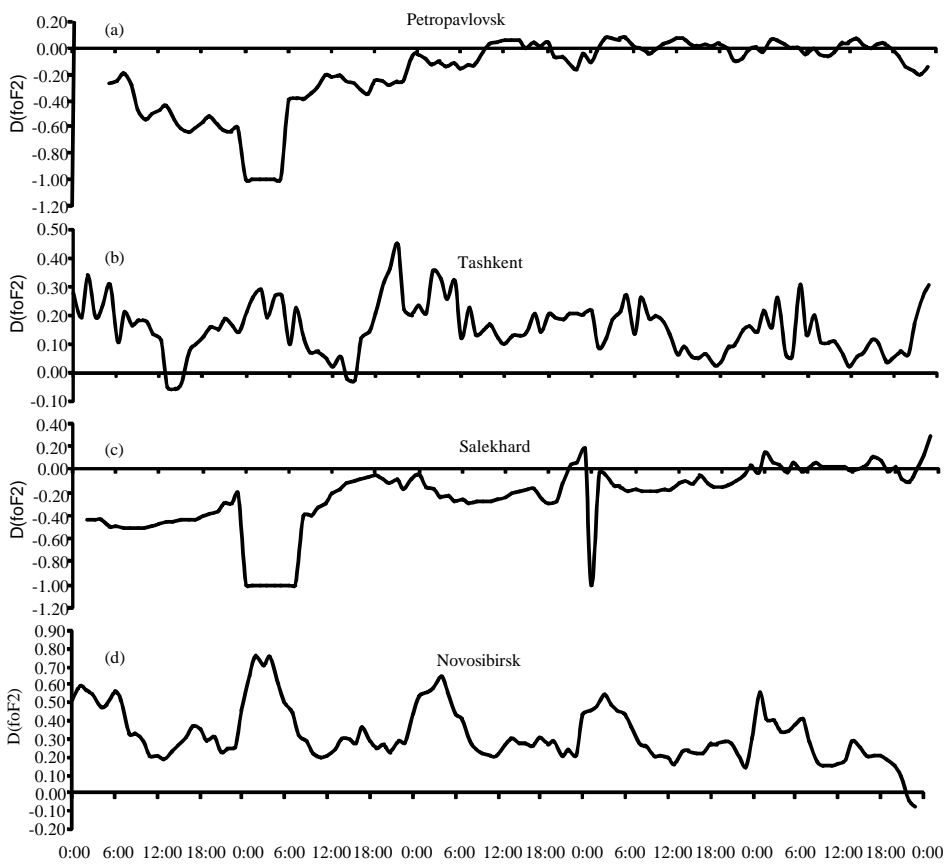
Time (UT)

Fig. 4: Continue 


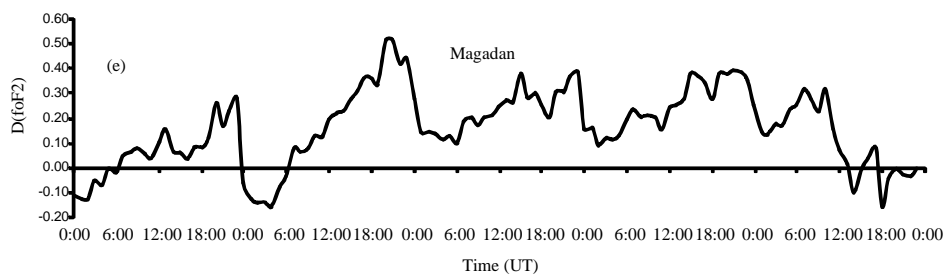

Fig. 4: a-e) The ionospheric observations of the storm of August 12-16, 2000

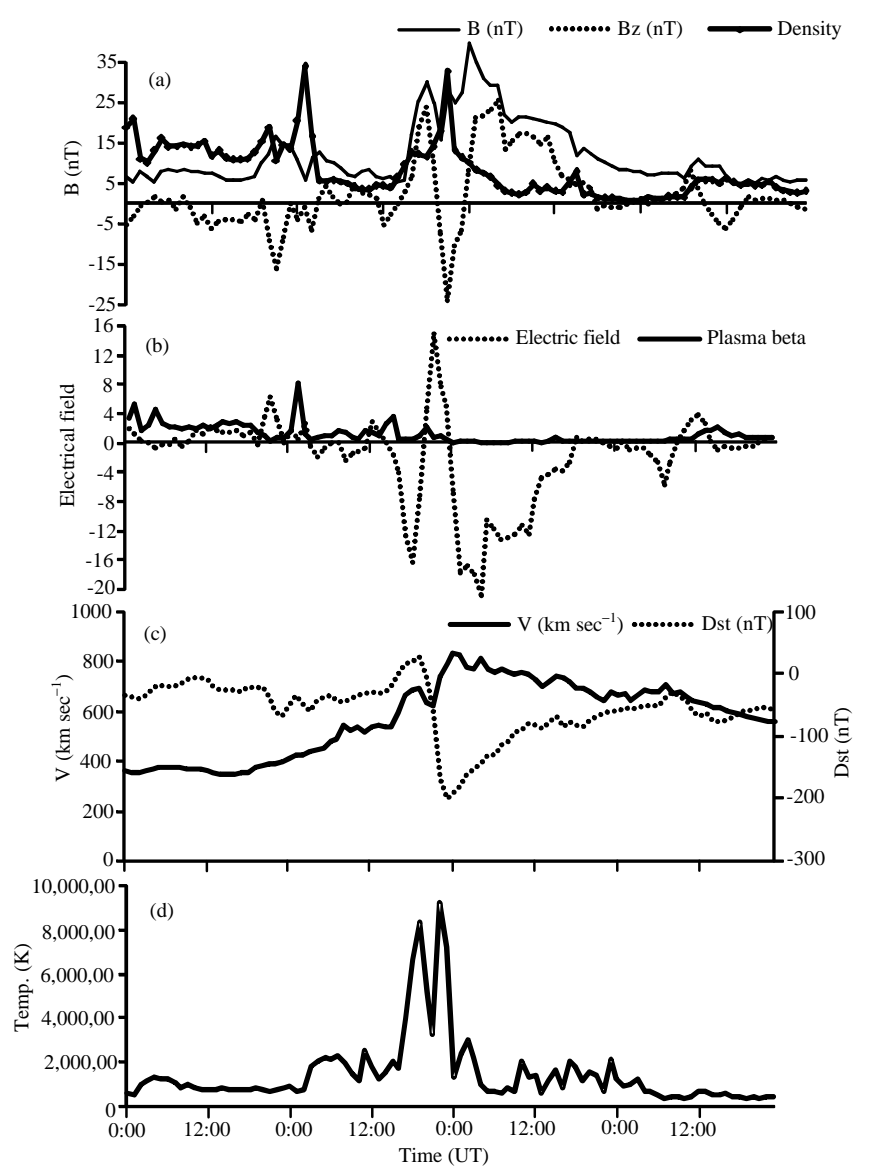

Fig. 5: a-d) Response plots of the geomagnetic, interplanetary and solar wind parameters for the storm of September 17, spanning $16-19,2000$

geomagnetic storm is most conveniently described in terms of the normalized deviations of the critical frequency foF 2 from the reference, $\mathrm{D}(\mathrm{foF} 2)$ (Chukwuma, 2003) where:

$$
D(\text { fo F } 2)=\frac{\text { foF2 }-(\text { foF } 2) \text { aver }}{(\text { foF2 }) \text { aver }}
$$

Hence, the data under analysis consists of $\mathrm{D}(\mathrm{foF} 2)$ of respective hourly values of foF 2 of February 12-16 (Fig. 6), August 12-16 (Fig. 7), September 17-21 (Fig. 8), October 5-9 (Fig. 9) and July 15-19 (Fig. 10), all in the year
2000. The reference for each hour (for each storm event) is the average value of foF 2 for that hour calculated from the five quiet days preceding the storm. Furthermore, the use of $D(f \circ F 2)$, the normalized deviations of the critical frequency rather than the critical frequency foF 2 itself provides a first-order correction for temporal, seasonal and solar cycle variations, so that geomagnetic storm effects are better identified. Note that in analyzing D (foF2) variations for ionospheric storms, positive and negative storms are defined by changes in amplitude, Danilov (2001) postulated that the maximum absolute value of $\mathrm{D}(\mathrm{foF} 2)$, of $>10 \%$ are regarded as intense activities. 

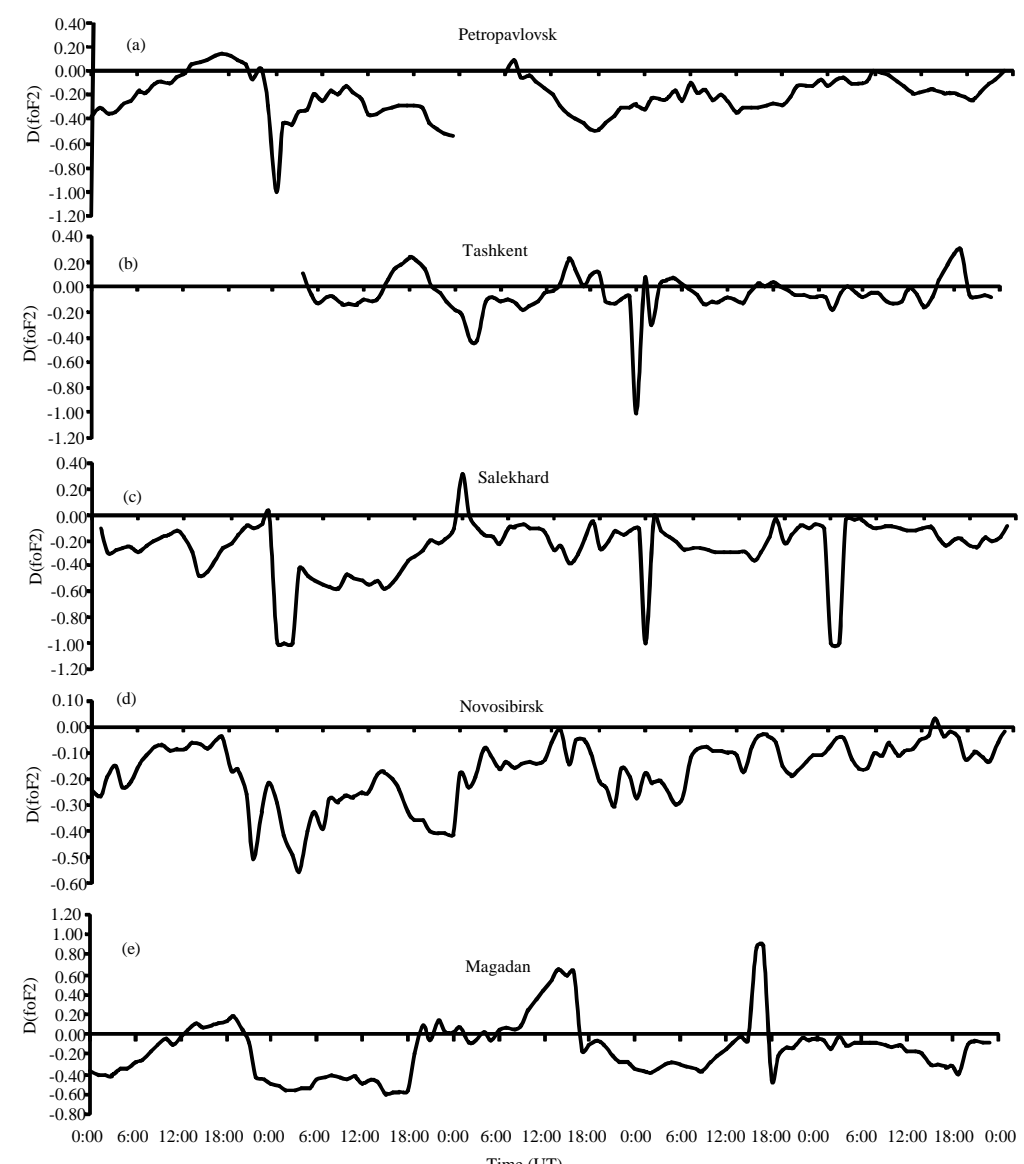
Time (UT)

Fig. 6: a-e) The Ionospheric observations for September 17-21, 2000
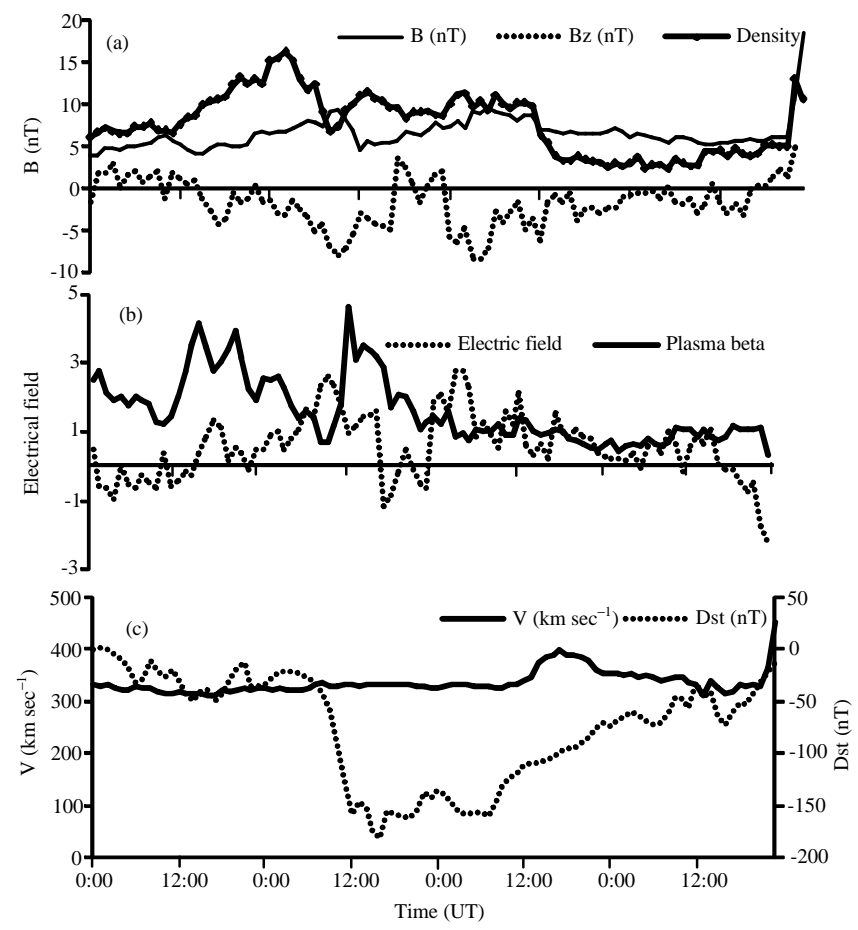

Fig. 7: Continue 


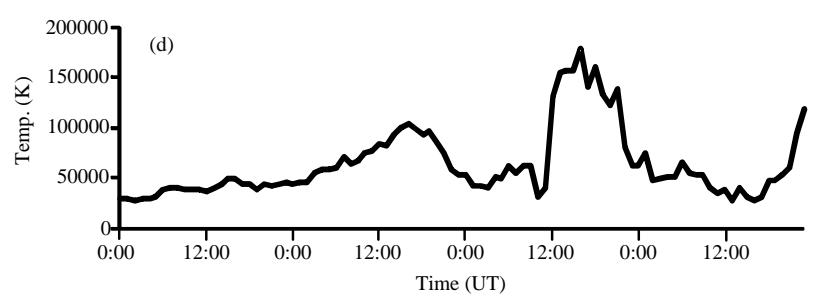

Fig. 7: a-d) Response plots of the geomagnetic, interplanetary and solar wind parameters for the storm of October 5, 2000, spanning October 4-7

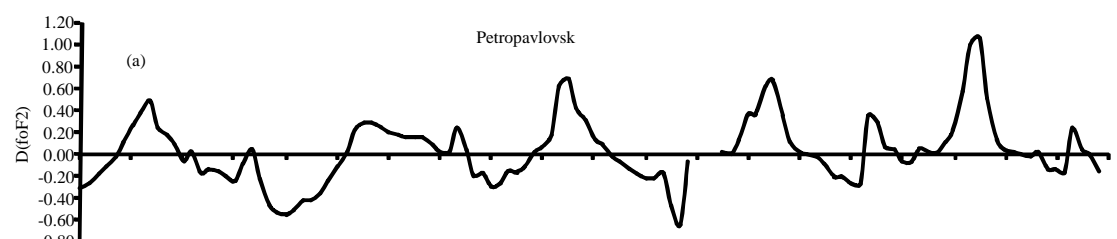

$-0.80$
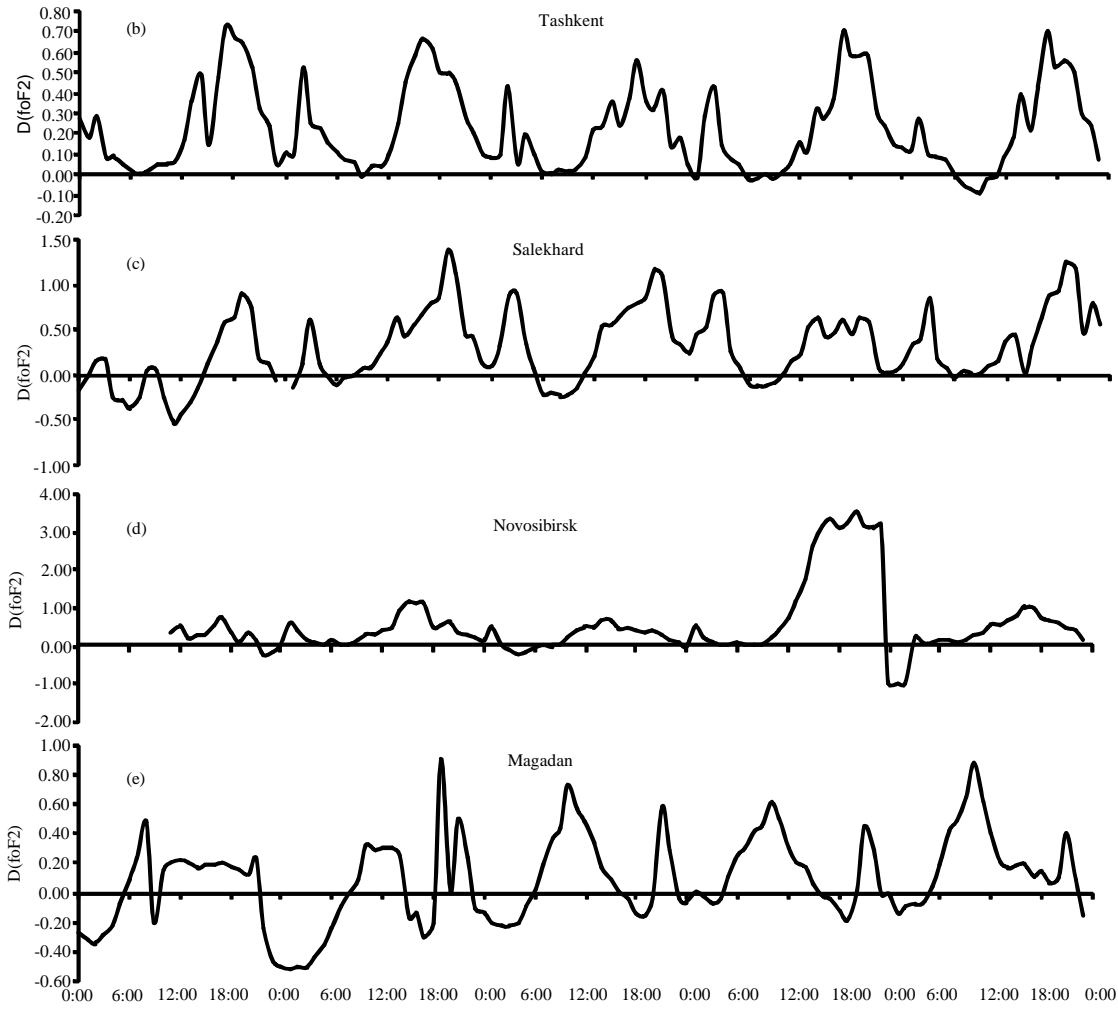

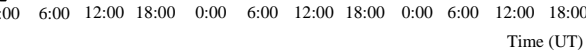

Fig. 8: a-e) The Ionospheric observations for October 5-9, 2000

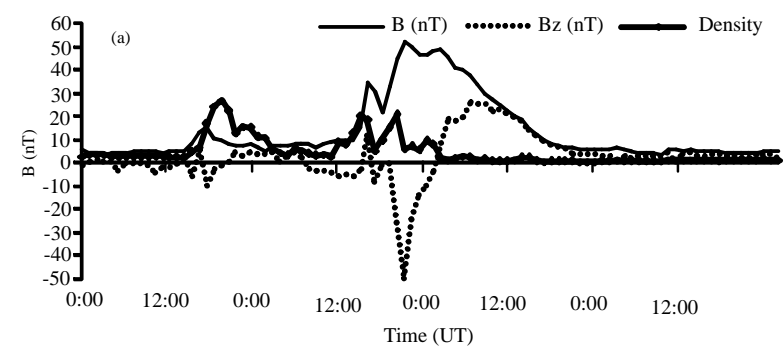

Fig. 9: Continue 

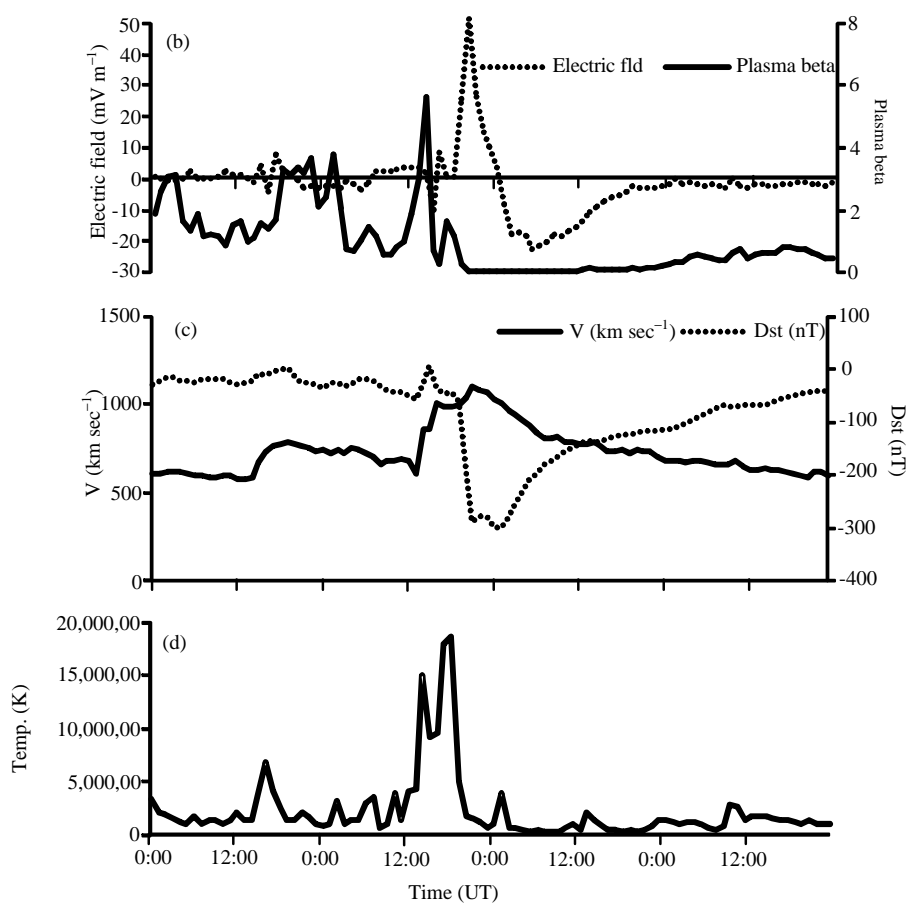

Fig. 9: a-d) Response plots of the geomagnetic, interplanetary and solar wind parameters for the storm of July 15, 2000 and spanning July 14-17, 2000
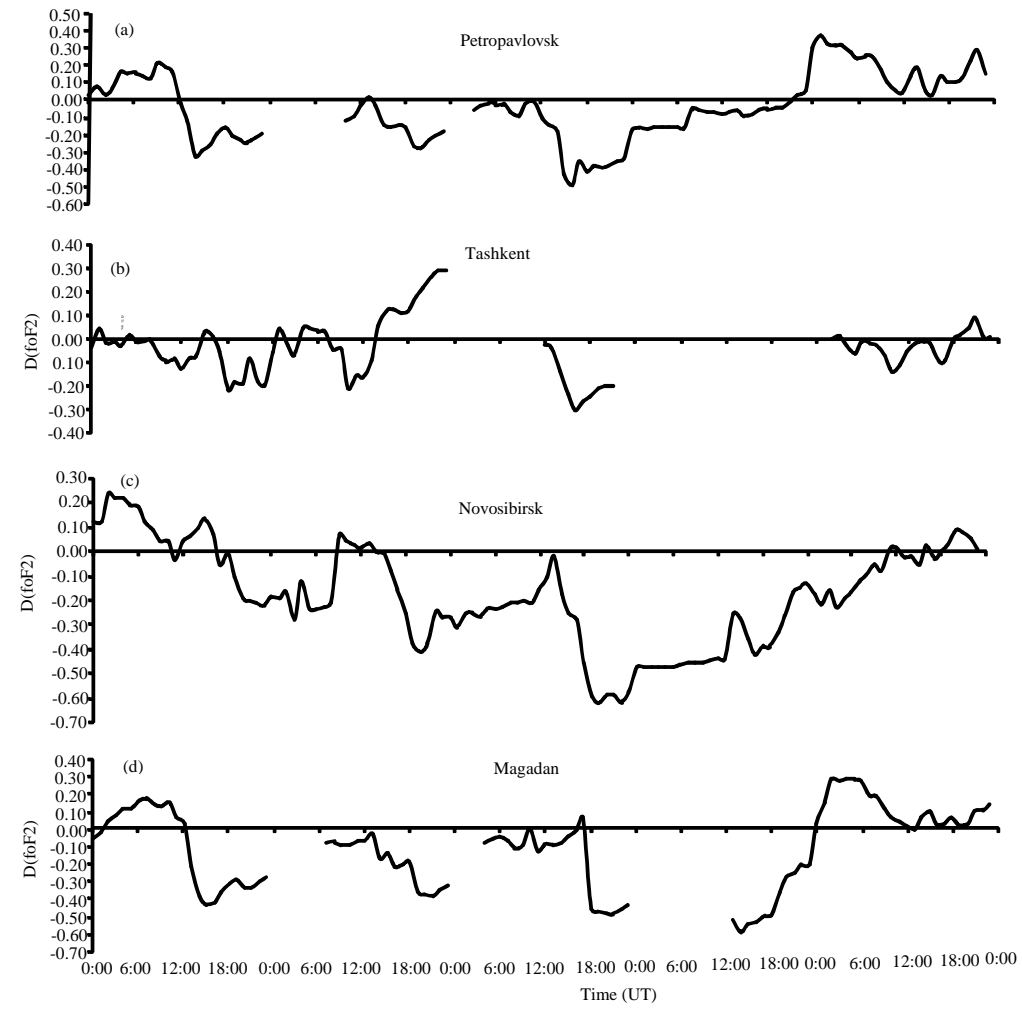

Fig. 10: a-d) The ionospheric observations for July 15-19, 2000 


\section{RESULTS}

\section{February 12, 2000 storm}

Interplanetary and geomagnetic observations: Figure 1 are the response plots of the geomagnetic, interplanetary and solar wind parameters for the storm of February 12, 2000. According to Buonsanto and Fuller-Rowell (1997), the principal defining property of a magnetic storm is the creation of an enhanced ring current, formed by ions (notably by protons and oxygen ions) and electrons in the 10-300 keV energy range, located between $2-7 R_{E}$ and producing a magnetic field disturbance which at the equator is opposite in direction to the earth's dipole field, thereby causing a diamagnetic decrease in the earth's magnetic field measured at near-equatorial magnetic stations as low-latitude magnetic index, Dst. From panel of Fig. 1, showing the average interplanetary magnetic field $\mathrm{B}$, the $\mathbb{M F} \mathrm{Bz}$ (GSM) and the plasma proton density, it was observed that both $\mathrm{B}$ and plasma proton density followed the same pattern. It should be noted that both variables began to drop Southwardly at the instance the Dst (part c) began its main activity dropping to its peak minimum value of $-133 \mathrm{nT}$ on Feb. 12 around $1100 \mathrm{UT}$. This is indicated by the vertical line that drops through the whole figure. It is well established that the $\mathrm{Bz}$ component of the IMF exerts the most important influence on the magnetoshere and high-latitude ionosphere, as it controls the fraction of the energy in the solar wind which is extracted by the magnetosphere. Furthermore when $\mathrm{Bz}$ is strongly negative, magnetic reconnection between the IMF and the geomagnetic field produces open fields which allowed for mass, energy and momentum to be transferred from the solar wind to the earth's magnetosphere. Here, the IMF Bz experiences a sinusoidal wave-like pattern until around 1800 UT of February 11 when it turns totally Southward, after it had experienced a shock in the interplanetary medium, obtaining its peak minimum value of $-14.1 \mathrm{nT}$. Note also the increase in the solar plasma flow speed (part c) to a value of $568 \mathrm{~km} \mathrm{sec}^{-1}$ within the same period as well as the increase in the plasma proton density. It should be noted also that the relatively slow rising stream above $400 \mathrm{~km} \mathrm{sec}{ }^{-1}$ indicate the arrival of shocks (Strickland et al., 2001). According to Gonzalez et al. (2001, 2002), intense magnetic storms occur when the solar flow speed is substantially higher than the average speed of $400 \mathrm{~km} \mathrm{sec}^{-1}$. It was also observed that before the actual storm event, the Dst variations indicate that weak storm dominated throughout most of the period 0000 UT on Feb. 11 to 0000 UT on Feb 12 at which time the $\mathrm{Bz}$ orientation is northward. On the temperature panel (part d), it was observed that immediately after the shock was experienced in the interplanetary medium as indicated on the Dst plot, the plasma temperature abruptly rose to a value of about $380000 \mathrm{~K}$ around $0600 \mathrm{UT}$ on Feb 11. The structure of this geomagnetic storm event is further made clearer by the plasma beta (part c). The plasma beta plot shows a relatively low value between 1200 UT through $2300 \mathrm{UT}$ on Feb. 12. Given this low values which is coincident with low plasma temperature and an enhanced plasma flow speed, the profile of the plasma beta appears to present a criterion for magnetic clouds. Hence, it can be stated that the storm is generated by shocks from magnetic cloud origin which is characterized by low beta plasma, high IMF magnitude and large scale coherent field rotations often including large and steady North-South components. However in due course, it was discovered that the North-South component of the interplanetary magnetic field regulated the growth of the ring current. Regarding the electric field, the primary causes of geomagnetic storm at the earth according to Gonzalez et al. (1994) are strong dawn-to-dusk electric fields associated with the passage of Southward magnetic fields Bs past the earth for a sufficiently long interval of time. It was observed from the Fig. 1 (part b) that the electric field rose to a value of $8.00 \mathrm{mV} \mathrm{m}^{-1}$ at the instance the $\mathrm{Bz}$ turns Southward. It has been proposed by Chao-Song et al. (2005) that when the IMF turns Southward and remains stably Southward for several hours, the dayside Eastward ionospheric electric field is enhanced throughout the entire interval of Southward IMF and that a similar enhancement of the Westward ionospheric electric field is observed when the IMF turns Northward and remains stably Northward. In this case, the ionospheric electric field enhancement lasts for $>1 \mathrm{~h}$ without significant decay, so it is termed the long-duration enhancement of the ionospheric electric field.

Ionospheric response: Moreover, the ionospheric observations to the storm of February 12, 2000 are shown in Fig. 2 and it spans 12-16 February. From Fig. 2, it was observed that generally for all the stations, it was more of an enhancement in the foF 2 ionosphere (i.e., positive phase storm) but more pronounced at the high latitude stations of Magadan and Salekhard, as well as at Petropavlovsk. It is well established that the $\mathrm{Bz}$ component of the IMF is the most important influence on the magnetoshere and high and mid-latitude ionosphere as it controls the fraction of the energy in the solar wind which is extracted by the magnetosphere.

Therefore, the positive storm experienced at the high and mid latitude stations after storm commencement appear to be caused by the short duration Southward 
turning of $\mathrm{Bz}$ giving $\delta \mathrm{Bz}=-14 \mathrm{nT}$ between 0600 and 1100 UT on February 12. It thus appear that this Southward turning with $\delta \mathrm{Bz}-14 \mathrm{nT}$ may have been accompanied by an increase in solar wind dynamic pressure which led to an enhanced coupling between the solar wind and the terrestrial magnetosphere that significantly increased the geoeffectiveness of the solar wind (Chukwuma, 2007). According to Davis et al. (1997), although negative IMF is important in enabling the extraction of solar wind energy and thus driving global ionosphere/thermosphere disturbances, the solar wind energy density must be high for coherent changes to be seen at mid-latitudes. Chao-Song et al. (2002) recently found that variations in mid-latitude ionosphere are well correlated with variations in IMF. From Fig. 2, the significant increases of the mid-latitude ionospheric $\mathrm{F}$ region electron density experienced over Petropavlovsk, Tashkent and Novosibirsk started to occur at 1200 UT on 12 February 2000, almost immediately after the SSC (as indicated on the Dst plot in Fig. 1) and lasted for $>7 \mathrm{~h}$ during the daytime. This case may be classified as a long-duration positive storm phase. Observe also that thereafter the $\mathrm{F} 2$ region experiences a short term depletion level to about $10 \%$ in all the stations for just about $5 \mathrm{~h}$, before they began to pick up again. It was further shown that all the ionospheric stations experiences depletion in the F2 layer at the exact time, the Dst recorded its minimum peak value (i.e., 1100 UT on February 12). One striking feature is the electron density depletion recorded at all stations around 0600 UT of each day between 12-16 February.

\section{August 12, 2000 storm}

Interplanetary, geomagnetic and ionospheric observations: The interplanetary and geomagnetic observations to the storm of 12 th August 2000 are shown in Fig. 3, spanning August 11-14. Figure 3a showing the respective plots of $\mathrm{B}, \mathrm{Bz}$ and proton density, it was observed that the average magnetic field $B$ attained its peak value of $33.6 \mathrm{nT}$ around $0900 \mathrm{UT}$ on August 12. This coincides with the peak depression value on the IMF Bz plot to a value of $-28.7 \mathrm{nT}$, as well as the minimum peak value on the Dst plot (part c). Note also that the $\mathrm{Bz}$ orientation was mostly Southward throughout the whole of August 11 through 1700 UT of August 12. However as the storm began to recover, the $\mathrm{Bz}$ turned northward and maintain this posture till the 2300 UT of August 14. The instance the $\mathrm{Bz}$ abruptly turned northward to a value of $10.7 \mathrm{nT}$ which also corresponds to the Dst value of $-24 \mathrm{nT}$ around 0000 UT on August 11 marked the onset of the SSC during which little energy was entering the magnetosphere, regardless of the speed and number density of particles in the solar wind. More importantly, it was discovered that SSC is not a necessary condition for a storm to occur and hence the initial phase is not an essential feature. It is thus evident that the most essential feature of a storm is the significant development of a ring current and its subsequent decay. From Fig. 3C showing the plots of the flow speed, it was shown that the flow speed suddenly rose from $515 \mathrm{~km} \mathrm{sec}^{-1}$ around 1900 UT on August 11 to $613 \mathrm{~km} \mathrm{sec}^{-1}$ of the same day and thereafter to $644 \mathrm{~km} \mathrm{sec}^{-1}$ around $0500 \mathrm{UT}$. It has been agreed that the power required to build up the storm time ring current and to supply the dissipation associated with various auroral and ionospheric manifestations of storms and substorms must be extracted ultimately from the kinetic energy of solar wind flow. Therefore, the observed increase in the flow speed value just immediately after SSC can be attributed to the conversion of the solar wind which is initially in electromagnetic form to mechanical energy of particle motion (either flow or thermal) whereas the energy supplied by the solar wind is initially all in mechanical form. According to Kamide et al. (1998), energy flow from the solar wind to the magnetosphere and ionosphere must therefore proceed in two steps: mechanical energy from the solar wind is converted to electromagnetic energy (and can be viewed as stored in the magnetic field primarily of the magnetotail) and this electromagnetic energy is converted to mechanical energy of particles in the plasma sheet, ring current and ionosphere. Thus, the observed higher plasma proton density and higher flow speed combine to form a much larger solar wind ram pressure. Moreover, the 11 August 2000 event thus indicates that the magnetosphere is much more sensitive to solar wind dynamic pressure variations when the IMF is strongly Southward than when it is weakly Southward.

Given the low values of plasma beta (part b) and temperature (part d) which is coincident with an enhanced plasma flow speed between 1100 and 2300 UT on August 12 , the profile of the plasma beta appears to present a criterion for magnetic clouds. Hence, it can be stated that the storm of August 12, 2000 is generated by shocks from magnetic cloud origin which is characterized by low beta plasma, high IMF magnitude and large scale coherent field rotations often including large and steady North-South components. Given the variations of the solar wind parameters under investigation, it is safe to suggest that the same magnetospheric process played the leading role in the enhancement in the ring current. Moreover according to Tsurutani, magnetic clouds that are geoeffective have a Southward and then Northward (or vice versa) magnetic field directional variation. When the magnetic cloud has a very high velocity, it 
compresses the plasma ahead of it and forms a collissionless shock. Behind this shock is a sheath which contains heated plasma and compressed magnetic fields. These intense sheath magnetic fields in turn can also cause magnetic storms.

Regarding the ionospheric response (Fig. 4), Danilov (2001) had suggested that the response of the ionospheric $\mathrm{F} 2$ region to magnetospheric disturbances is different from that of the lower ionosphere. The difference is due to the differences in physical mechanisims responsible for the changes of the electron concentration (e). While in the $\mathrm{E}$ and $\mathrm{D}$ regions the primary reason of the (e) changes is the variation of the ionization rate because of corpuscular intrusions, there is no considerable change of the ionizing source intensity in the $\mathrm{F} 2$ region during geomagnetic disturbances. From Fig. 4, spanning August 12-14, 2000, it was observed from the $\mathrm{D}(\mathrm{foF} 2)$ plot that there is a decrease in the ionospheric foF 2 at Petropavlovsk and the high latitude station of Salekhard. However, there is an enhancement (i.e., positive storm) at Tashkent, Novosibirk and Magadan.

From the Bzplot in Fig. 3a, a change in $\mathrm{Bz}$ of $\delta \mathrm{Bz}=$ $-16.8 \mathrm{nT}$ was observed between 0300 and $0800 \mathrm{UT}$ on August 12 which appear to coincide with increases in both plasma density and flow speed. This change in $\mathrm{Bz}$ could lead to the explanation of ionospheric responses observed at some stations hours after it occurred. This is because Davis et al. (1997) have shown that a Southward turning with a change in $\mathrm{Bz}$ of $\delta \mathrm{Bz}=-11.5 \mathrm{nT}$ results in foF 2 showing a marked decrease in amplitude, reaching a minimum value few hours after the Southward turning. Hence, the positive storm experienced at Tashkent, Novosibirsk and Magadan after storm commencement appear to be caused by the short duration Southward turning of $\mathrm{Bz}$ giving $\delta \mathrm{Bz}=-16.8 \mathrm{nT}$ between 0300 and 0800 UT on August 12.

Kamide et al. (1998) had proposed that changes in the large-scale electric field during magnetic storms, both substorm related and directly driven by the solar wind, can trap particles well inside geosynchronous orbit. Recent satellites observations in the inner magnetosphere have shown, however that the abundance of ionospheric ions (particularly $\mathrm{O}^{+}$) is high and is highly correlated with substorm activity. This $\mathrm{O}^{-}$dominance coupled with the fact that a significant fraction of $\mathrm{H}^{+}$is also ionospheric in origin suggests that the cause of the intense ring current during great storms is the enhanced outflow of ionospheric ions.

Solar IMF activity and ionospheric observations to the September 17, 2000 storm: The solar and interplanetary magnetic field activities and the Ionospheric observations to the storm of September 17, 2000 storm are shown in Fig. 5 and 7, respectively. According to Adebesin (2008) while investigating the roles of interplanetary and geomagnetic parameters in the generation of intense $(-250 \mathrm{nT} \leq$ peak Dst $<-100 \mathrm{nT})$ and very intense (peak Dst $<-250 \mathrm{nT}$ ) magnetic storms, it was revealed that the interplanetary magnetic field $\mathrm{Bz}$ plays a prominent role alongside Dst in the generation of intense storms. Moreover, the interplanetary electric field $(-\mathrm{V} \times \mathrm{Bz})$ associated with high speed streams and the solar wind density $\mathrm{Np}$ (which is a function of the solar wind ram pressure) also plays an important role in the ring current intensification. He went further to propose that in regards to the geoeffectiveness of the flow speed $V$, the Bs and Bs interval $\left(\mathrm{B}_{\mathrm{T}}\right)$ with the average magnetic field $\mathrm{B}$, it was observed that generally for all the storms, the flow speed is the most correlated, showing a correlation coefficient of $50.9 \%$ with B, Furthermore, the result shows that very intense storms whose main feature is a plasma flow speed $>550 \mathrm{~km} \mathrm{sec}^{-1}$ has a negligible correlation between the flow speed and the magnetic field $B$ whereas, intens' storms have a $58.7 \%$ correlation between the two parameters. Adebesin (2008) finally argued that all very intense storms are likely to have a plasma flow speed $>550 \mathrm{~km} \mathrm{sec}^{-1}$ within the storm interval but not all flow speed $>550 \mathrm{~km} \mathrm{sec}^{-1}$ are very intense storms. The last assertion is true for the storm of September 17, 2000. From Fig. 5, the Dst plot (part c) revealed the minimum peak value for these storm event (i.e., $-201 \mathrm{nT}$ ) and the corresponding flow speed value (part c) revealed $794 \mathrm{~km}$ $\mathrm{sec}^{-1}$. The high value recorded by the average magnetic field B (part a) together with the increment in the flow speed V value (27.5 nT) around 2300 UT of September 17 also points to the fact there is a good correlation between the two parameters, especially when it satisfies the intense storms condition.

It must be noted that the plasma temperature (Fig. 5d) showed a tremendous increase to a value of $920518 \mathrm{~K}$, at the instance of the minimum peak value of the Dst around 2300 UT of September 17 which also heralded the high flow speed rate, as well as a Southward turning of the electric field (Fig. 5b) and low plasma beta. Note also that the temperature was initially minima between 0000 UT of September 16 and 1300 UT of September 17. All these appear to indicate that the storm is as a result of interplanetary ejecta of the magnetic cloud type. It has been said that the dominant solar/coronal events that occur near the maximum sunspot phase of the solar cycle are impulsive ejecta, often referred to as Coronal Mass Ejections (CMEs). These events have different speeds but the ones that are most effective in creating magnetic storms are fast events with speeds exceeding the ambient 
wind speed by the magnetosonic wave speed thus, forming a fast forward shock. As a fast plasma and field structure propagates from the sun through interplanetary space, it sweeps up and compresses the slower plasma and field ahead thus creating a sheath between the shock and the interplanetary manifestation of the ejecta. This condition holds for the storm of September 17, 2000. It can therefore be said that the sheath created is as a result of the $\mathrm{Bz}$ Southward orientation around 1700 UT on September 18, few hours to the storms main phase. This is because if an intense storm (like the one under investigation here) has a long-duration Southward field intervals in either the sheaths or the ejecta itself, a main phase may follow. It is also important to note that in several occasions; $>1$ interplanetary structure can be associated with the origin of intense storms which are complex in nature. These complex structures have been studied by different scientists (Gonzalez et al., 2001). Also, most of these reported complex structures involve a fast forward shock followed by a magnetic cloud and usually another high speed stream is found in the magnetic cloud (Dal Lago et al., 2001). In a study by Adebesin and Chukwuma (2008), while studying the variation between Dst and IMF Bz during intense and very intense geomagnetic storms, it was observed that very intense storms are more likely to experience shock in the interplanetary magnetic field region faster than intense storms with a flow speed $>400 \mathrm{~km} \mathrm{sec}^{-1}$. It was also observed that intense storms recover faster than the very intense ones. Regarding the ionospheric observations (Fig. 6), it was observed from the $\mathrm{D}(\mathrm{foF} 2)$ that a depletion at an F2 layer maximum (negative ionospheric storm) was predominant at all the five ionospheric stations of Petropavlovsk, Tashkent, Salekhard, Novosibirsk and Magadan. However, it is pertinent to state that there was a transient positive phase storm at Magadan between 0900 and 1400 UT on September 19. This could be as a result of composition changes which directly influence the electron concentration in the F2 region. However, the circulation may spread the heated gas to lower latitudes which may eventually result in the observed general negative storm. It could also be explained on the bases of Danilov (2001) conclusion, that during geomagnetic disturbances, a large amount of energy is deposited into the thermosphere at high latitudes that leads first of all, to an increase of the neutral gas temperature (depletion on the atoms-tomolecules ratio). Both factors may contribute to a decrease of the electron concentration (the negative phase of an ionospheric storm) in the high latitude ionosphere. The energy deposit thereafter produces a strong enough storm-induced circulations which is directed equatorward and may coincide or conflict with the quite-time circulation. Accordingly, the gas with depleted $[\mathrm{O}] /\left[\mathrm{N}_{2}\right]$ is brought far the latitude in order for the negative storm to spread equatorward. Observe that at all the stations (except Tashkent, that is short of data) recorded their main electron concentration depletion between the hours of 2100 UT of September 17 and 0300 UT of September 18.

\section{October 5, 2000 storm}

Interplanetary, geomagnetic and ionospheric observations: The interplanetary and geomagnetic observations are shown in Fig. 7 spanning October 4-7. From the Dst plot (part c), the Dst got to its first minimum peak value of $-182 \mathrm{nT}$ at $1600 \mathrm{UT}$ on October 5. It could therefore be argue that the solar wind became geoeffective a day before the storm day. According to Kamide et al., (1998), if a new major particle injection occurs, it leads to a further development of the ring current with Dst index decreasing. It should also be noted that the increases in both plasma density (part a) and flow speed around this period are indicative of arrival of a shock in the interplanetary medium. It was also observed that the solar wind speed increased towards the storm day, far above a value of $350 \mathrm{~km} \mathrm{sec}{ }^{-1}$. Kane had proposed earlier that moderate or strong storms occurred only when solar wind speed was above $\sim 350 \mathrm{~km} \mathrm{sec}^{-1}$. The plot thereafter shows the arrival of another shock in the interplanetary medium making the Dst (which originally is setting up to recover) to reach its second minimum value of $-157 \mathrm{nT}$ at $\sim 0500$ UT on October 6 . According to Gonzalez and Tsurutani, a major storm occurs when the IMF experiences more than three hours and $>10 \mathrm{nT}$ Southward component. This is further indicated by the first decrease in Dst at 1600 UT of October 5. Therefore, the Dst plot presents a double step main phase event taking $>24 \mathrm{~h}$ to develop. The 1 st step of the main phase with Dst $-182 \mathrm{nT}$ starts at $2100 \mathrm{UT}$ on October 4. Also, the 2nd step is associated with the sharp Southward turning of $\mathrm{Bz}$ at 0000 UT on October 6, reaching a value of $-5.7 \mathrm{nT}$ (Fig. 7). Also, after $\mathrm{Bz}$ had reached its peak value of $-8.3 \mathrm{nT}$ around $0400 \mathrm{UT}$ October 6 , it began rotating towards the North direction whereas this decrease in the intensity of the Southward component of the IMF is followed by a recovery in Dst. The long duration of $\mathrm{Bz}$ in the Southward direction for $>12$ $h$ is an indication that the storm event is intense in nature. According to Danilov (2001), the IMF structures leading to intense magnetic storms have intense $(>10 \mathrm{nT})$ and long duration $(>3 \mathrm{~h}$ ) Southward component. The Dst profile for this storm event also appears to present a type 2 intense geomagnetic storm. However, a type 2 


\section{J. Eng. Applied Sci., 7 (4): 306-325, 2012}

storm must satisfy the following two conditions (Kamide et al., 1998): the first decrease in Dst should partly subside before the second decrease follows sometime later. If $M$ represents the magnitude of the first Dst decrease while $\mathrm{R}$ quantifies Dst recovery then $\mathrm{M}>\mathrm{R}>0 \mathrm{nT}$. Furthermore, $\mathrm{R} / \mathrm{M}<0.9$. The two peaks in Dst must be separated by $>3 \mathrm{~h}$ i.e., $\mathrm{T}+\mathrm{T} 1>3 \mathrm{~h}$. Here, $\mathrm{T}$ is the duration of recovery for the first storm while $\mathrm{T} 1$ is the duration of the main phase of the second storm. Presently with the Dst plot here, $\mathrm{M}=182 \mathrm{nT}, \mathrm{R}=138 \mathrm{nT}$, this implies that $\mathrm{M}>\mathrm{R}>0 \mathrm{nT}$ and $\mathrm{R} / \mathrm{M}(138 / 182=0.76)<0.9$. Also, $\mathrm{T}+\mathrm{T} 1=14 \mathrm{~h}$ (between $1500 \mathrm{UT}$ of October 5 and $0500 \mathrm{UT}$ of October 6). Therefore, $\Delta \mathrm{T}=\mathrm{T}+\mathrm{T} 1=14>3 \mathrm{~h}$. These results confirm that the intense storm of October 5 is a type 2 storm. Moreover, the structure of the geomagnetic storm of October 5, 2000 is shown further by the, plasma beta, electric field and plasma temperature. It was observed that there is a high value of plasma beta and plasma temperature on October 5. Hence, it can be inferred from this that the shock was followed by ejecta which was not a magnetic cloud type (Dal-Lago et al., 2004). Figure 8 is the ionospheric responses to the October 5, 2000 storm. Figure 8 shows more of a positive phase storm at the high latitude stations of Salekhard and Magadan, as well as the mid-latituude stations of Tashkent, Novosibirsk and Petropavlovsk.

However, there is a preceeding negative phase storm observed at the two high latitude stations of Salekhard and Magadan, as well as at Petropavlovsk between 0000 and $0600 \mathrm{UT}$ of October 5, as well as between 0000 and 0600 UT of October 6 . However, the observed mid-latitude F2-layer positive storm effect in the daytime could be attributed to the vertical plasma drift increase, resulting from the interaction of background (poleward) and storminduced (equatorward) thermospheric winds but not to changes of $(\mathrm{O})$ and $\left(\mathrm{N}_{2}\right)$ concentrations. This is because different longitudinal sectors marked by the storm onset as night-time and daytime demonstrate different F2-layer positive storm mechanisms. Neutral composition changes in the night-time sector with increased (O) and $\left(\mathrm{N}_{2}\right)$ absolute concentrations while $(\mathrm{N} / 2 \mathrm{O})$ storm/ $\left(\mathrm{N}_{2} / \mathrm{O}\right)$ quietlapproxl at F2-layer heights are shown to contribute largely to the background $\mathrm{NmF} 2$ increase at lower latitudes lasting during daytime hours. Storminduced surges of the equatorward wind give rise to an additional $\mathrm{NmF} 2$ increase above this background level.

\section{Geomagnetic storm of 15 July, 2000}

Solar and IMF activity on 14-18.July: A major magnetic storm was observed on 15 July, 2000 with the Dst values down to $-300 \mathrm{nT}$. The storm began around $1600 \mathrm{UT}, 15$ July, 2000. The Dst reached its minimum value $(-300 \mathrm{nT})$ around 2300 UT on the same day. Recovery of the storm took about 3 days. Figure 9 shows the response of interplanetary, geomagnetic and solar wind parameters for July 14-18, 2000. This kind of event according to Dal Lago et al. (2001) is known as the Bastilla event in which case it consists of an interplanetary shock driven by a magnetic cloud whose intense magnetic field rotates from South to North smoothly. While the $\mathrm{Bz}$ is pointing Southward, it causes a very intense fall in the Dst value reaching its minimum peak value of $-301 \mathrm{nT}$. It should be noted that immediately after the shock, there was a sudden rise in the plasma temperature (part d), plasma density (part a), as well as an increase in the value of the flow speed to $\sim 880 \mathrm{~km} \mathrm{sec}^{-1}$. On July 14 the solar wind shows a fairly flat although high, speed with a falling density and temperature.

On the 14th day, the plasma parameters stay fairly flat until about 1530 UT when there is a clear forward shock with a speed increase to $>700 \mathrm{~km} \mathrm{sec}^{-1}$. This is followed by a sudden density increase and temperature decrease near $1700 \mathrm{UT}$. On the 15 th, there is a declining speed until a large forward shock arrives near $1400 \mathrm{UT}$.

This shock is clearly identified by the abrupt and strong speed increase from about 600 to $>900 \mathrm{~km} \mathrm{sec}^{-1}$. This shock has a strong density and stronger temperature enhancement. On the 16th day, the speed continues to be quite high, with an interesting and substantial decrease occurring at about 0140 UT and lasting until 0210 UT. During this decrease, the density also falls and the electric field increased. This storm is interplanetary ejecta of the magnetic cloud type which could be as a result of possible association between CME and an interplanetary event. Associated with this flare was a full halo CME, observed by the LASCO instrument with an expansion speed of $2177 \mathrm{~km} \mathrm{sec}^{-1}$.

Ionosphere disturbances following the geomagnetic storm on 15 July, 2000: Figure 10 is the ionospheric response to the geomagnetic storm of 15 July, 2000. From the ionospheric D (foF2) plot, it was observed that generally for all the stations under consideration, there is a decrease in the electron density $(\mathrm{NmF} 2)$ at a maximum of the ionospheric F2 layer, thereby resulting in a negative phase storm. Note that the appearance of the short-lived positive storms (enhancement) at the high latitude station of Magadan between 0100 and 0800 UT 15th July and 2200 UT 18 th July till 0600 UT 19th July $>28 \%$ as well as the mid-latitude station of Tashkent between 1500 and 2200 UT on 16 th July 2000 up to $29 \%$ could be as a result of energy being injected into the polar upper atmosphere as the solar wind become geoeffective which in turn launches a Traveling Atmospheric Disturbance (TAD) 


\section{J. Eng. Applied Sci., 7 (4): 306-325, 2012}

which propagates with high velocity (Adebesin and Bakare, 2008). This TAD carries along equatorwarddirected winds of moderate magnitude. At high latitudes, these meridional winds drive ionization up inclined magnetic field lines and cause uplifting of the $\mathrm{F}$ layer, leading to an increase in the ionization density. The observed decrease in foF 2 during the storm is related to the neutral composition disturbances. Heating at auroral and high latitudes causes expansion of the neutral atmosphere and enhanced neutral winds carry disturbed composition. However, enhancement in the mean molecular mass in the neutral composition disturbance zone leads to an increase in the loss rate of ions, resulting in a decrease of the ionospheric plasma density and thus a negative storm. Strickland et al. (2001) had shown that negative ionospheric storm effects are indeed correlated with the region of enhanced molecular mass. Observations have shown a general good correlation between $\left(\mathrm{O} / \mathrm{N}_{2}\right)$ and negative ionospheric storms (Prolss and Craven, 1998).

Numerical simulation outputs from global first principles models such as the Thermosphere Ionosphere General Circulation Model (TIGCM) (Burns et al., 1995) and the Coupled Thermosphere Ionosphere Model (CTIM) (Fuller-Rowell et al., 1996) have shown clear association of decreases in the mean molecular mass with increases in $\mathrm{NmF} 2$ during geomagnetic active periods.

However, whether the compositional perturbation is fully responsible for the negative storm effects is still an open question. Some have suggested that perturbations in neutral gas composition are the main cause for negative ionospheric storms (Prolss and Werner, 2002) while others have suggested that vibrationally excited $\mathrm{N}_{2}$ as it can enhance the $\mathrm{O}+$ recombination rate, may be important in explaining the negative storm effects (Pavlov et al., 1999). On simultaneity, it was observed that between 1200 and 1500 UT 15th July, 1200 and 1400 UT 16th July as well as 1200 and 2300 UT 17 th July 2000 , there are some degrees of simultaneity in the observed decrease in foF 2 at all the stations.

The lack of averaged hourly data marked the areas where there appear to be gap in the plots. Note also that no data was recorded at Salekhard within the plotted period.

\section{DISCUSSION}

Now researchers consider the effects of ionization depletion at an F2 layer maximum (negative ionospheric storm) observed at all stations during the respective storms of 17th September, 2000 and 15th July, 2000 as well as the ionospheric stations of Petropavlovsk and
Salekhard during the storm of 12th August, 2000. It was first suggested by Gordienko et al. (2005) that neutral composition changes in the thermosphere as a main reason for the decrease in $\mathrm{NmF} 2$ during negative ionospheric storms. Later it became apparent that physical mechanisms are driving this decrease. Rapid heating of the polar atmosphere during energy income from the magnetosphere generates a vertical ascent of the air (upwelling) through the surfaces of constant pressure. According to them, this ascent leads to a deviation from the diffusive equilibrium and to an increase in the mean molecular mass that is to a decrease in the ratio of the atomic oxygen density $(\mathrm{O})$ to the molecular nitrogen $\left(\mathrm{N}_{2}\right)$ and molecular oxygen $\left(\mathrm{O}_{2}\right)$ densities. Expansion of a heated region also leads to a formation of pressure gradients changing the thermospheric circulation. An increased equatorward wind however brings the air with a changed composition to the middle latitudes, increasing there the mean molecular mass. Moreover, originating gradient winds usually play a more important role at night because they are added to the background wind in the global atmospheric circulation (day-night). The winds often have the form of waves or Traveling Atmospheric Disturbances (TADs) when the energy comes in the form of a single pulse. Atmospheric disturbances are shown in the ionosphere in the form of Traveling Ionosphere Disturbances (TIDs) registered in ionograms. As a result, the atmospheric region with a changed composition reaches mid-latitudes at night and then rotates together with the earth into the dawn sector. Since the photoionization rate is proportional to the $O$ density, whereas the loss rate is proportional to the $\mathrm{N}_{2}$ and $\mathrm{O}_{2}$ densities, the increase in the mean molecular mass leads to a decrease in the electron density $(\mathrm{NmF} 2)$ at a maximum of the ionospheric F2 layer. The velocity of TAD motion considerably exceeds the wind velocity therefore, the TIDs caused by heating of the polar atmosphere are first registered at mid-latitude stations and are then followed by an ionospheric storm. Hence, the reason for the observed negative ionospheric storm. The $\mathrm{F}$ peak electron density in the mid-latitude ionosphere may be reduced by a factor of 2-5 during negative storm phases.

However, positive storms have not been well understood. Increases in the ionospheric $\mathrm{F}$ region electron density during positive storms show different characteristics and several mechanisms have been proposed to explain the observations. Positive storms may be classified into several categories depending on duration, local time and latitude (Chao-Song et al., 2005). It must be noted that the type of a frequently observed positive storm is the daytime short-duration increases in the mid-latitude ionospheric electron density i.e., the one 


\section{J. Eng. Applied Sci., 7 (4): 306-325, 2012}

experienced at the mid-latitude stations of Tashkent and Novosibirsk between 0100 and 0400 UT 12th August during the storm of August 12,2000 (Fig. 4) as well as the one at Petropavlovsk and Magadan between 0800 and 1000 UT 15 th July during the storm of July 15,2000 (Fig. 10). However, short-duration increases occur a few hours after a Storm Sudden Commencement (SSC) or a substorm (Jakowski et al., 1999; Prolss, 1993). The simulations of Chao-Song et al. (2005) show that atmospheric disturbances (large-scale gravity waves) are launched in the auroral zone during storms or substorms and travel to the mid-latitude ionosphere. The traveling atmospheric disturbances move the $\mathrm{F}$ region ionization upward to higher altitudes along the geomagnetic field lines, resulting in slower loss rates and higher electron densities. Note that the increases in the mid-latitude ionospheric $\mathrm{F}$ region electron density and Total Electron Content (TEC) are often observed in local dusk sector during magnetic storms and termed dusk effect. This is because the uplifting of the $\mathrm{F}$ layer by an eastward electric field and convergence in the East-West direction might be responsible for the dusk effect (Chao-Song et al., 2005). However, the resultant density enhancements at the equatorward edge of the dusk-sector ionospheric trough were termed Storm Enhanced Density (SED). Foster et al. (2002) have compared measurements of SED with the Millstone Hill radar, the global GPS receiver network and the DMSP satellites. They find that the SED density enhancements in the dusk sector are associated with the erosion of the outer plasmasphere by subauroral polarization stream electric fields and that the SED plumes can map directly into the plasmaspheric tail observed with the IMAGE spacecraft. Storm-time increases of the F region electron density are observed also in the nightside (near midnight) mid-latitude ionosphere. It was proposed that downward plasma fluxes from the plasmasphere into the underlying ionosphere could cause significant enhancements in the $\mathrm{F}$ region electron density. Sojka et al. (2002) showed that a persistent electric field can also cause strong positive storm phases near midnight at middle latitudes. The $\mathrm{F}$ region electron density in the equatorial ionosphere and at the anomaly latitudes can be increased or decreased during magnetic storms. Moreover, Adeniyi (1986) found that increases in $\mathrm{NmF} 2$ over the equator during the main and first recovery phases of storms seem to be more common than decreases; the increases in $\mathrm{NmF} 2$ were interpreted as the consequence of a downward motion of the F2 layer and reduced fountain effect caused by an enhanced Westward electric field. Furthermore, Chao-Song et al. (2005) showed that atomic oxygen concentration increases in the equatorial thermosphere may be the main reason for a positive $\mathrm{NmF} 2$ storm effect. Foster and Rich (1998) while investigating the mid-latitude ionospheric electric field and $\mathrm{F}$ region electron density during a storm, found a large increase of the electron density over Arecibo and a significant decrease of the electron density over the equator and suggested that an enhanced eastward electric field caused the disturbances in the ionosphere. Another type of positive storms is the long-duration increase in the $\mathrm{F}$ region electron density or TEC at middle and low latitudes. Tanaka (1979) found that positive regions occurred at lower magnetic latitudes in equatorial fronts of spreading negative regions over a couple of days. They suggested that thermospheric disturbances originating in the polar region spread equatorward with the progress of storms, creating positive phases in front of the spreading disturbances by the effect of wind and negative phases by the effect of enhanced molecular composition. The possible mechanisms that may be responsible for the observed long-duration positive storm at all the ionospheric stations from the $\mathrm{D}$ (foF 2 ) plots during the 12 th February, 2000 (Fig. 2) and at Tashkent, Salekhard and Novosibirk during the 5th October 2000 geomagnetic activities (Fig. 8) can now be fully explained. A widely accepted mechanism for daytime positive storm phases at mid-latitudes is equatorward wind disturbances that can uplift the F region plasma (Jakowski et al., 1999; Prolss, 1993; Lu et al., 2001). In the case, the respective solar wind flow speed and the electric field plots in Fig. 1 (storm of 12th February) and Fig. 7 (storm of 5th October 2000) measurements show that there was no large equatorward wind during the daytime, so the electron density increases cannot be attributed to equatorward disturbance winds. Another mechanism proposed by Chao-Song et al. (2005) is related to changes in the mean molecular mass. Enhanced heat inputs in the auroral zone during storms cause upwelling and drive equatorward winds that carry away energy absorbed by the upwelling. This energy is released by the compressional heating due to downwelling at lower latitudes. The upwelling, equatorward winds and downwelling cause increases in the $\mathrm{N}_{2} / \mathrm{O}$ ratio at high latitudes and decreases in the $\mathrm{N}_{2} / \mathrm{O}$ ratio at low latitudes. This shows that the positive phase thus observed may not be caused by a decrease in the $\mathrm{N}_{2} / \mathrm{O}$ ratio for some reasons. One of the most striking reason is that if the energy transfer is carried by equatorward neutral winds, it will take several hours for disturbance winds originating in the auroral zone to reach middle latitudes to cause the decrease of the mean molecular mass. However on the contrary, the observed 
positive phase started to occur just after the SSC and any variations of molecular mass caused by storm-associated winds at middle latitudes could not be generated within such a short time. However, the only process that can quickly propagate from high to low latitudes without obvious delay according to Chao-Song et al. (2005) is the penetration of electric fields.

Foster and Rich (1998) and Foster et al. (2005) suggested that a storm-time enhanced Eastward electric field uplifted the ionospheric plasma particles, causing a decrease of the electron density over the equator and an increase of the electron density at the anomaly latitudes. An Eastward electric field will move the mid-latitude ionospheric $\mathrm{F}$ region plasma to higher altitudes with lower recombination resulting in increases of the electron density. It is therefore suggested that this action may be responsible for the observed long-duration positive storm for the 12th February, 2000 and 5th October, 2000 geomagnetic activities.

It has been shown that the fast solar wind ions in the magnetosheath have limited entry into the magnetosphere and instead tend to flow down the flanks of the magnetosphere. This leaves a slow solar wind component that is better able to convect into the inner magnetosphere. These particles track the prevailing two-cell convection pattern. The particles remain at low energies as they convect over the polar cap. When they reach the convection reversal region they experience strong heating as they head sunward. Some of the particles of the dawn side appear to cross to the dusk side to produce the most energetic solar wind contribution to the symmetric ring current.

The biggest loss of these energized particles occurs when they again reach the subsolar region where they first enter. At this point, the ions appears to reenter the reconnection region and are either acceleration around the flanks via the low-latitude boundary layer or back over the cap and into the mantle via new reconnected field lines. The issue of speed is also important to the heavy ions within the solar wind which show a higher percentage of penetration into the inner magnetosphere than for the solar wind protons (Winglee, 2003).

Geoeffectiveness of ionosphere with interplanetary and solar wind parameters: Figure 11 showed the regression plot for ionospheric $\mathrm{D}$ (foF2) variations with $\mathrm{Dst}$, plasma flow speed $\mathrm{V}$ and IMF Bz, respectively for each of the 5 ionospheric stations and is made clearer in Table 3. Table 3 however, shows the deviation of the ionospheric critical frequency $D(f \circ F 2)$ variations for each of the 5 geomagnetic storm events at the 5 stations with corresponding values of Dst, flow speed and $\mathrm{Bz}$ at Dst minimum peak value. Moreover shown in Table 4 are the correlation coefficients of $\mathrm{D}(\mathrm{foF} 2)$ variations during each of the 5 storm events against the Dst, $\mathrm{V}, \mathrm{Bz}$ and $(\mathrm{V} \times \mathrm{Bz})$, respectively for each of the 5 stations. It was observed from Table 4 that with regards to the ionospheric response correlation with Dst, the high latitude station of Magadan recorded $73.2 \%$ followed by Novosibirsk with 59.7 correlation percentage. The least was recorded at Salekhard (i.e., 13\%). In relation to the flow speed V, it was observed that all the stations had a good correlation ( $>58 \%$ ) with the F2 ionosphere with the exception of only Petropavlovsk that recorded a rather negligible correlation percentage. The correlation percentage between $\mathrm{D}$ (foF 2 ) and IMF Bz however recorded $85.8 \%$ at Salekhard and $68.0 \%$ at Taskent. Petropavlovsk recorded a negligible correlation percentage here as well. The calculated averaged value for each plotted variable (i.e., Dst, Vand $\mathrm{Bz}$ ) is the sum total for each variable divided by 5 (i.e., number of stations). Note that the average correlation percentage for the F2 ionosphere against the Dst, flow speed $\mathrm{V}$ and $\mathrm{Bz}$ are 40.5, 60.3 and 46.4, respectively.

The implication of these is that the plasma flow speed is suggested to be the most geoeffctive parameter with the F2 ionosphere, irrespective of the latitudinal position (This is yet to be established for low latitudes as low latitude is not considered here). It has been said that the solar wind is regarded as the driver for all forms of geomagnetic storms.

However, the relationship between solar wind induced dawn-dusk electric fields $E$ and the flow speed is given by $\mathrm{E}=\mathrm{V} \times \mathrm{Bz}$ (i.e., these electric fields are caused by a combination of solar wind velocity and Southward IMF). Meanwhile, Tsuurutani had suggested that of these two parameters, the Southward IMF is probably the more important because of its far greater variability. In spite of this (i.e., to show this validity), a correlation column was also created for $\mathrm{V} \times \mathrm{Bz}$ against the deviation of the $\mathrm{F} 2$ critical frequency $\mathrm{D}(\mathrm{foF} 2)$ for the 5 stations (Table 4).

From the Table 4, it was observed that the high latitude station of Salekhard had the highest percentage correlation with $71.4 \%$, followed by Magadan (60.4\%), Tashkent (42.3\%), Novosibirk (10\%) and Petropavlovsk (negligible). From these, the following were deduced: the increase in percentage correlation of $\mathrm{V} \times \mathrm{Bz}$ against $\mathrm{D}$ (foF 2 ) is directly proportional to the increase in the latitudinal position of each station (i.e., the highest percentage is from the highest latitude station of Salekhard); the stations with more occurrences of electron density enhancemet (positive phase storms) are those whose altitudes are $>100 \mathrm{~m}$; an average value of $37.5 \%$ 

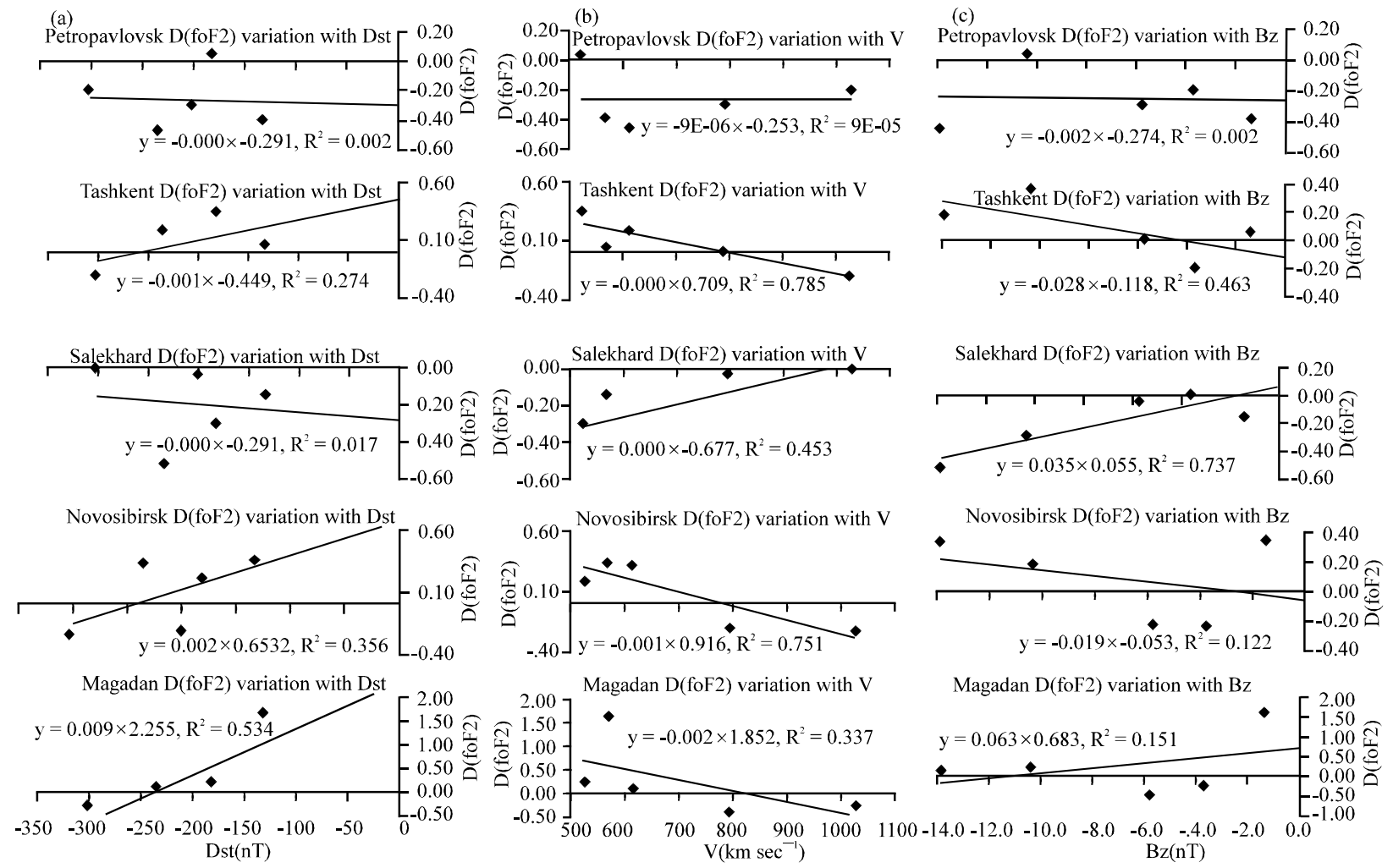

Fig. 11: a-c) Showing the regression plot for ionospheric $\mathrm{D}(\mathrm{foF} 2)$ variations with; a) Dst (left column); b) With plasma flow speed V (middle column); c) With IMF Bz (right column) for each of the 5 ionospheric stations

Table 3: Deviation of the ionospheric critical frequency $\mathrm{D}(\mathrm{foF} 2)$ variations for each of the 5 storm events for each of the 5 stations at peak Dst time with corresponding values of $\mathrm{Dst}$, flow speed and $\mathrm{Bz}$

\begin{tabular}{|c|c|c|c|c|c|c|c|c|c|}
\hline \multirow[b]{2}{*}{ Storm date } & \multirow[b]{2}{*}{ Peak Dst } & \multirow[b]{2}{*}{$\mathrm{V}\left(\mathrm{km} \mathrm{sec}^{-1}\right)$} & \multirow[b]{2}{*}{$\mathrm{Bz}$} & \multirow[b]{2}{*}{ Peak Dst time } & \multicolumn{5}{|c|}{ Ionospheric stations $\mathrm{D}(\mathrm{foF} 2)$ variations } \\
\hline & & & & & Petropavlovsk & Tashkent & Salekhard & Novosibirsk & Magadan \\
\hline Feb. 12, 2000 & -133 & 568 & -1.4 & 11.000 & -0.39 & 0.05 & -0.14 & 0.34 & 1.63 \\
\hline Jul. 15,2000 & -301 & 1030 & -3.7 & 23.000 & -0.20 & -0.20 & 0.00 & -0.23 & -0.27 \\
\hline Aug. 12, 2000 & -235 & 613 & -13.9 & 09.000 & -0.46 & 0.19 & -0.51 & 0.33 & 0.08 \\
\hline Sep. 17,2000 & -201 & 794 & -5.8 & 23.000 & -0.29 & 0.22 & -0.03 & -0.21 & -0.45 \\
\hline oct. 05,2000 & -182 & 523 & -10.4 & 13.000 & 0.04 & 0.36 & -0.30 & 0.19 & 0.21 \\
\hline
\end{tabular}

Table 4: Correlation coefficient of $\mathrm{D}(\mathrm{foF} 2)$ variations during each of the 5 storm events versus Dst, $\mathrm{V}, \mathrm{Bz}$ and $(\mathrm{V} \mathrm{x} \mathrm{Bz})$, respectively for each of the 5 stations.

\begin{tabular}{|c|c|c|c|c|c|c|c|c|}
\hline Stations & $\begin{array}{l}\text { Latitude } \\
\text { position }\end{array}$ & $\begin{array}{c}\text { Altitude } \\
(\mathrm{m})\end{array}$ & $\begin{array}{l}\mathrm{D}(\mathrm{foF} 2) \\
\text { vs Dst }\end{array}$ & $\begin{array}{l}\mathrm{D}(\mathrm{foF} 2) \\
\text { vs V }\end{array}$ & $\begin{array}{l}\mathrm{D}(\mathrm{foF} 2) \\
\text { vs Bz }\end{array}$ & $\begin{array}{c}\mathrm{D}(\mathrm{foF} 2) \\
\mathrm{vs}(\mathrm{V} \times \mathrm{Bz})=\mathrm{E}\end{array}$ & $\begin{array}{l}\text { No. of +ve } \\
\text { phase storm }\end{array}$ & $\begin{array}{l}\text { No. of -ve } \\
\text { phase storm }\end{array}$ \\
\hline Petropavlovsk & Middle & 50 & 0.044 & 0.009 & 0.044 & 0.032 & 2 & 3 \\
\hline Tashkent & Middle & 480 & 0.523 & 0.886 & 0.680 & 0.423 & 3 & 2 \\
\hline **Salekhard & High & 66 & 0.130 & 0.673 & 0.858 & 0.714 & 2 & 2 \\
\hline Novosibirsk & Middle & 111 & 0.597 & 0.867 & 0.349 & 0.100 & 3 & 2 \\
\hline Magadan & High & 610 & 0.731 & 0.581 & 0.389 & 0.604 & 3 & 2 \\
\hline Averaged & - & - & 0.405 & 0.603 & 0.464 & 0.375 & - & - \\
\hline
\end{tabular}

No data available for this station during the July 15,2000 storm

correlation for $\mathrm{V} x$ Bz versus $\mathrm{D}$ (foF2) showed that it is $\mathrm{V}$ that is more geoeffective, otherwise (i.e., if it were to be $\mathrm{Bz}$ ), the percentage value would have been $\geq 50 \%$. Sojka et al. (2002) had showed that a persistent electric field can cause strong positive storm phases near midnight at middle latitudes.

\section{CONCLUSION}

The effects of ionization depletion at an F2 layer maximum observed at all stations during the respective storms of 17th September, 2000 and15th July, 2000 as well as at Petropavlovsk and Salekhard during the storm of 


\section{J. Eng. Applied Sci., 7 (4): 306-325, 2012}

12th August, 2000 could be attributed to the rapid heating of the polar atmosphere during energy income from the magnetosphere which generates a vertical ascent of the air (upwelling) through the surfaces of constant pressure. This ascent in turn leads to a deviation from the diffusive equilibrium and to an increase in the mean molecular mass, that is to a decrease in the ratio of the atomic Oxygen density $(\mathrm{O})$ to the molecular Nitrogen $\left(\mathrm{N}_{2}\right)$ and molecular oxygen $\left(\mathrm{O}_{2}\right)$ densities which could be as a result of increased equatorward wind. However for positive storms, it must be noted that the type of a frequently observed positive storm is the daytime short-duration increases in the mid-latitude ionospheric electron density i.e., the one experienced at the mid-latitude stations of Tashkent and Novosibirk between 0100 and 0400 UT 12th August during the storm of August 12,2000 as well as the one at Petropavlovsk and Magadan between 0800 and 1000 UT 15 th July during the storm of July 15, 2000. Meanwhile, the possible mechanisms that may be responsible for the observed long-duration positive storm at all the ionospheric stations from the $\mathrm{D}($ foF 2$)$ plots during the 12th February, 2000 (Fig. 2) and at Tashkent, Salekhard and Novosibirsk during the 5th October, 2000 geomagnetic activities (Fig. 8) can be explained on the basis that the respective solar wind flow speed and the electric field plots in Fig. 1 (storm of 12 th February) and 7 (storm of 5th October, 2000) measurements show that there was no large equatorward wind during the daytime, so the electron density increases cannot be attributed to equatorward disturbance winds (as opposed to the general theory that a widely accepted mechanism for daytime positive storm phases at mid-latitudes is equatorward wind disturbances that can uplift the $\mathrm{F}$ region plasma (Jakowski et al., 1999; Lu et al., 2001). A good reason for these is that if the energy transfer is carried by equatorward neutral winds, it will take several hours for disturbance winds originating in the auroral zone to reach middle latitudes to cause the decrease of the mean molecular mass. However on the contrary, the observed positive phase started to occur just after the SSC and any variations of molecular mass caused by storm-associated winds at middle latitudes could not be generated within such a short time.

However, the only process that can quickly propagate from high to low latitudes without obvious delay according to Chao-Song et al. (2005) is the penetration of electric fields. An eastward electric field will move the mid-latitude ionospheric $\mathrm{F}$ region plasma to higher altitudes with lower recombination, resulting in increases of the electron density. It is therefore suggested that this action may be responsible for the observed longduration positive storm for the 12th February and 5th October 2000 geomagnetic activities. On the geoeffectiveness of Ionosphere with interplanetary and solar wind parameters, it was observed that with regards to the ionospheric response correlation with Dst, the high latitude station of Magadan recorded $73.2 \%$ followed by Novosibirsk with 59.7 correlation percentage. The least was recorded at Salekhard (i.e., 13\%). In relation to the flow speed $\mathrm{V}$, it was observed that all the stations had a good correlation $(>58 \%$ ) with the $\mathrm{F} 2$ ionosphere with the exception of only Petropavlovsk that recorded a rather negligible correlation percentage. The correlation percentage between $\mathrm{D}(\mathrm{foF} 2)$ and IMF $\mathrm{Bz}$ however recorded $85.8 \%$ at Salekhard and $68.0 \%$ at Taskent. Petropavlovsk recorded a negligible correlation percentage here as well.

The average correlation percentage for the F2 ionosphere against the Dst, flow speed $\mathrm{V}$ and $\mathrm{Bz}$ are 40.5 , 60.3 and 46.4, respectively. The implication of these is that the plasma flow speed is suggested to be the most geoeffctive parameter with the $\mathrm{F} 2$ ionosphere, irrespective of the latitudinal position (This is yet to be established for low latitudes, as low latitude is not considered here). On the relationship between solar wind induced dawn-dusk electric fields $E$ and the flow speed which is given by $\mathrm{E}=\mathrm{V} \times \mathrm{Bz}$, a correlation column was created for $\mathrm{V} \times \mathrm{Bz}$ against the deviation of the $\mathrm{F} 2$ critical frequency $\mathrm{D}$ (foF2) for the 5 stations, it was however observed that the high latitude station of Salekhard had the highest percentage correlation with $71.4 \%$, followed by Magadan (60.4\%), Tashkent (42.3\%), Novosibirsk (10\%) and Petropavlovsk (negligible). From these, the following were deduced: the increase in percentage correlation of $\mathrm{V} \mathrm{x} \mathrm{Bz}$ against $\mathrm{D}$ (foF2) is directly proportional to the increase in the latitudinal position of each station; the stations with more occurrences of electron density enhancemet (positive phase storms) are those whose altitudes are $>100 \mathrm{~m}$; an average value of $37.5 \%$ correlation for $\mathrm{V} \mathrm{x} \mathrm{Bz}$ versus $\mathrm{D}$ (foF2) showed that it is $\mathrm{V}$ that is more geoeffective, otherwise (i.e., if it were to be $\mathrm{Bz}$ ), the percentage value would have been $=50 \%$.

\section{ACKNOWLEDGEMENTS}

The hourly interplanetary, geomagnetic and solar wind parameters used in this research were made possible by the data from the NSSDC's OMNI database (http://nssdc.gsfc.nasa.gov/omniweb) and also the daily values of ionosonde data for all stations were obtained 
from the National Geophysical Center's SPIDR (http://spidr.ngdc.noaa.gov) for which the researcher is grateful.

\section{REFERENCES}

Adebesin, B.O and N.O.Bakare, 2008. Ionospheric response to geomagnetic activity in high latitude at different sectors of the world. Niger. J. Space Res., 5: 42-54.

Adebesin, B.O. and V.U. Chukwuma, 2008. On the variation between Dst and IMF Bz during 'intense' and 'very intense' geomagnetic storm. Acta Geod. Geoph. Hung., 43: 1-15.

Adebesin, B.O., 2008. Roles of interplanetary and geomagnetic parameters in 'intense' and 'very intense' magnetic storms generation and their geoeffectiveness. Acta. Geod. Geoph. Hungarica., 43: $383-408$.

Adeniyi, J.O., 1986. Magnetic storm effects on the morphology of the equatorial F2-layer. J. Atmos. Terr. Phys., 48: 695-702.

Buonsanto, M.J. and T.J. Fuller-Rowell, 1997. Strides made in understanding space weather at Earth. EOS Trans. Am. Geophys. Union, 78: 1-1.

Burns, A.G., T.L. Kileen, G.R. Carignan and R.G. Roble, 1995. Large enhancements in the O/N2 ratio in the evening sector of the winter hemisphere during geomagnetic storms. J. Geophys. Res., 100: 14,66114,671 .

Chao-Song, H., J.C. Foster and P.J. Erickson, 2002. Effects of solar wind variations on the midlatitude ionosphere J. Geophys. Res., 107: 1192-1192.

Chao-Song, H., J.C., Foster, L.P. Goncharenko, P.J. Erickson, W. Rideout and A.J. Coster, 2005. A strong positive phase of ionospheric storms observed by the Millstone Hill incoherent scatter radar and global GPS network. J. Geophys. Res., 110: A06303-A06303.

Chukwuma, V.U., 2003. Interplanetary phenomenon, geomagnetic and ionospheric response associated with the storm of October 20-21, 1989. Acta Geophys . Pol., 51: 459-472.

Chukwuma, V.U., 2007. On positive and negative ionospheric storms. Acta Geod. Geoph. Hung., 42: 1-21.

Dal lago, A., L.E.A. Vieira, E. Echer, W.D. Gonzalez and A.L. Clua de Gonzalez et al., 2004. Great geomagnetic storms in the rise and maximum of solar cycle 23 . Brazillian J. Phys., 34: 1542-1546.

Dal lago, A., W.D. Gonzalez, A.L. Clua de Gonzalez and L.E.A. Vieira, 2001. Compression of magnetic clouds in the interplanetary space and reuse in their geoeffectiveness. J. Atmos. Sol. Terre. Phys., 63: 451-455.
Danilov, A.D., 2001. F2 region response to geomagnetic disturbance. J. Atoms. Sol. Terre. Phys., 63: 441-449.

Davis, C.J., M.N. Wild, Lockwood and Y.K. Tulmay, 1997. Ionospheric and geomagnetic responses to changes in IMF Bz: A superposed epoch study. Ann. Geophys., 15: 217-230.

Foster, J.C. and F.J. Rich, 1998. Prompt midlatitude electric field effects during severe geomagnetic storms. J. Geophys. Res., 103: 26,367-26,372.

Foster, J.C., A.J. Coster, P.J. Erickson, W. Rideout, F.J. Rich, T.J. Immel and B.R. Sandel, 2005. Redistribution of the Stormtime Ionosphere and the Formation of the Plasmaspheric Bulge, in Global Physics of the Coupled Inner Magnetosphere, AGU, Washington.

Foster, J.C., P.J. Erickson, A.J. Coster, J. Goldstein and F.J. Rich, 2002. Ionospheric signatures of plasmaspheric tails. Geophys. Res. Lett., 29: 1623-1623.

Fuller-Rowell, T.J., M.V. Codrescu, H. Rishbeth, R.J. Moffett and S. Quegan, 1996. On the seasonal response of the thermosphere and ionosphere to geomagnetic storms. J. Geophys. Res., 101: 2343-2353.

Gonzalez, W.D., A.L. Clua de Gonzalez, J.H.A. Sobral, Dal lago and L.E. Vieira, 2001. Solar and interplanetry causes of very intense storms. Atmos. Terr. Phys., 63: 403-412.

Gonzalez, W.D., B.T. Tsurutani, R.P. Lepping and R. Schwenn, 2002. Interplanetary phenomenoa associated with very intense geomagnetic storms. J. Amos. Sol. Terr. Phys., 64: 173-181.

Gonzalez, W.D., J.A. Joselyn, Y. Kamide, H.W. Kroehl, G. Rostoker, B.T. Tsurutani, and V.M. Vasyliunas, 1994. What is a geomagnetic storm?. J. Geophys. Res., 99: 5771-5792.

Gordienko G.I., V.V. Vodyannikov and A.F. Yakovets, 2005. Ionospheric disturbances over Alma-Ata during the October-November 2003 magnetic storms. J. Geophys. Res., 110: A09S35-A09S35.

Jakowski, N., S. Schluter and E. Sardon, 1999. Total electron content of the ionosphere during the geomagnetic storm on 10 January 1997. J. Atmos. Terr. Phys., 61: 299-307.

Kamide, Y., W. Baumjohann, I.A. Daglis, W.D. Gonzalez and M. Grande et al., 1998. Current understanding of magnetic storms: storm/substorm relationship. Geophys. Res., 103: 17705-17728.

Lu, G., A.D. Richmond, R.G. Roble and B.A. Emery, 2001. Coexistence of ionospheric positive and negative storm phases under northern winter conditions: A case study. J. Geophys. Res., 106: 24,493-24,504. 
Pavlov, A.V., M.J. Buonsanto, A.C. Schlesier and P.G. Richards, 1999. Comparison of models and data at Millstone Hill during the 5-11 June 1991 storm. J. Atmos. Sol. Terr. Phys., 61: 263-279.

Prolss, G.W. and J.D. Craven, 1998. Perturbations of the FUV dayglow and ionospheric storm effects. Adv. Space Res., 22: 129-134.

Prolss, G.W. and S. Werner, 2002. Vibrationally excited nitrogen and oxygen and the origin of negative ionospheric storms. J. Geophys. Res., 107: 1016-1016.

Prolss, G.W., 1993. On explaining the local time variation of ionospheric storm effects. Ann. Geophys., 11: 1-9.

Rodger, A.S., G.L. Wrenn and H. Rishbeth, 1989. Geomagnetic storms in the antarctic F-region, II. Physical interpretation. J. Atmos. Terr. Phys., 51: 851-856.
Sojka, J.J., M. David and R.W. Schunk, 2002. A midlatitude space weather hazard driven directly by the magnetosphere. J. Atmos. Sol. Terr. Phys., 64: 687-695.

Strickland, D.J., R.E. Daniel and J.D. Craven, 2001. Negative ionospheric storm coincident with DE-1 observed thermospheric disturbance on October 14, 1981. J. Geophys. Res., 106: 21049-21062.

Tanaka, T., 1979. The worldwide distribution of positive ionospheric storms. J. Atmos. Terr. Phys., 41: 103-110.

Winglee, R.M., 2003. Circulation of ionospheric and solar wind particle populations during extended Southward interplanetary magnetic field. J. Geophys. Res., 108: 1385-1385. 